\title{
Microstructures in Polymer Fibres for Optical Fibres, THz Waveguides, and Fibre-Based Metamaterials
}

\author{
Alexander Argyros \\ Institute of Photonics and Optical Science (IPOS), School of Physics, The University of Sydney, Sydney, NSW 2006, Australia \\ Correspondence should be addressed to Alexander Argyros; alexander.argyros@sydney.edu.au
}

Received 10 September 2012; Accepted 4 October 2012

Academic Editors: M. Hu and D. Kouznetsov

Copyright (C) 2013 Alexander Argyros. This is an open access article distributed under the Creative Commons Attribution License, which permits unrestricted use, distribution, and reproduction in any medium, provided the original work is properly cited.

\begin{abstract}
This paper reviews the topic of microstructured polymer fibres in the fields in which these have been utilised: microstructured optical fibres, terahertz waveguides, and fibre-drawn metamaterials. Microstructured polymer optical fibres were initially investigated in the context of photonic crystal fibre research, and several unique features arising from the combination of polymer and microstructure were identified. This lead to investigations in sensing, particularly strain sensing based on gratings, and short-distance data transmission. The same principles have been extended to waveguides at longer wavelengths, for terahertz frequencies, where microstructured polymer waveguides offer the possibility for low-loss flexible waveguides for this frequency region. Furthermore, the combination of microstructured polymer fibres and metals is being investigated in the fabrication of metamaterials, as a scalable method for their manufacture. This paper will review the materials and fabrication methods developed, past and current research in these three areas, and future directions of this fabrication platform.
\end{abstract}

\section{Introduction}

Polymers have been investigated as a platform for the fabrication of microstructured optical fibres (MOFs) since 2001 [1$5]$ in the context of the photonic crystal fibre (PCF) research that had begun five years earlier [6-9]. The original work on PCF was based on silica fibres and the key innovation of using holes running the length of an optical fibre to control light in unprecedented ways [9]. The interest in using polymers arose from the difference in material properties between polymers and silica and the possibilities this entailed [1]. This initial work on microstructured polymer optical fibres (mPOFs) aimed to investigate the implications of these differences in material properties on the fabrication methods, fibre designs, optical properties, and potential applications of these fibres. These new fibres would be compared to the two related established areas of silica-based PCF, having the microstructure in common, and conventional polymer optical fibres (POFs) [10], having the material in common. The underlying theme was to identify situations where the combination of these two elements, the polymer and microstructure, was more beneficial than either element alone.
Over the next decade, the work on mPOF matured, as with work on PCF in general. The fabrication techniques were formalised, and performance matching and exceeding those of commercial POF was achieved in comparable cases [1113]. The limitations and possible applications were identified, analysed, and understood to a great extent. Whilst this shifted the work on $\mathrm{mPOF}$ to the realm of technological development rather than scientific research, new areas were continually being identified in which the knowledge developed in the context of the optical fibre work could be applied to conduct new research. Two such areas are the emerging fields of terahertz frequency radiation and experimental investigations of metamaterials.

Work at terahertz frequencies, generally considered to cover the range of $0.1-10 \mathrm{THz}$ or wavelengths between $3 \mathrm{~mm}$ and $30 \mu \mathrm{m}$, has been increasing due to the relatively recent availability of affordable and practical terahertz sources and detectors, bridging the so-called "terahertz gap" which had previously resulted in this part of the spectrum being underutilised. Interest in terahertz radiation arises from many potential spectroscopy and imaging applications for medical imaging and security [14-18]. It is nonionising radiation 
that can easily penetrate ordinary packaging materials like plastics, leather, and cardboard. Whilst the availability of sources and detectors has enabled recent work in this area, other optical components remain primitive in comparison to optics (i.e., for the visible and infrared).

Polymers were identified as a material of interest for work at terahertz frequencies [19], and particularly in work relating to waveguides [20]. The connection to microstructured polymer optical fibres was obvious, both in terms of the physics of waveguides and in terms of the material processing and fabrication techniques that had been developed. This is an area of active research aiming to deliver optical fibre-like waveguides for use at terahertz frequencies, as currently no such equivalent exists. This is a challenging prospect due to the differences between common material properties at terahertz frequencies as compared to the visible and infrared, and the broader spectral range and larger wavelengths of terahertz radiation.

The connection to metamaterials research was made by identifying that microstructured fibres produce large volumes of material with micron-sized features (the holes inside the fibre). Metamaterials, meaning "beyond" materials, are man-made composites with structure on a subwavelength scale that derive their properties from this structure rather than the materials from which that structure is constructed [21-25]. These composites are considered to consist of artificial "meta-atoms," and just as the individual atoms or molecules of an ordinary material determine its bulk properties, so these meta-atoms determine the bulk properties of metamaterials. As a result, unprecedented control of the relevant properties can be achieved through appropriate control of the structure of these meta-atoms.

For electromagnetic metamaterials, the properties of interest are the response to electric and magnetic fields, quantified by the permittivity and permeability, respectively. Hence, control over the permittivity and permeability is achieved through the structure, and a variety of properties not observed in naturally occurring materials have been demonstrated as a result. These include a magnetic response from nonmagnetic materials, and at high frequencies [22], and a negative refractive index [21, 23]. Electromagnetic metamaterials can in principle produce any combination of permittivity and permeability, and hence refractive index, potentially leading to other important applications such as lenses with resolution beyond the Rayleigh limit [26-28], and cloaking $[29,30]$, although the feasibility of some extreme applications remains unclear.

Electromagnetic metamaterials typically consist of metaldielectric composites. The subwavelength requirement on the size of the structure poses a practical problem, as metamaterials for the visible, infrared, or terahertz parts of the electromagnetic spectrum require structure on the scale of approximately $100 \mathrm{~nm}$ to $100 \mu \mathrm{m}$. Although fabrication methods capable of such resolutions exist, such as lithography techniques at the $100 \mathrm{~nm}$ scale [31], or inkjet printing on the $100 \mu \mathrm{m}$ scale [32], they produce planar (2D) metamaterials and are not capable of the inexpensive largevolume fabrication that may be required in the future for any practical applications. The extension of $\mathrm{mPOF}$ research to metamaterials aims to address this by combining metals with the large volumes of microstructure that is produced by drawing fibre. This allows metamaterials to be explored through a fabrication method that is intrinsically scalable and can lead to 3D bulk metamaterials.

This paper aims to present a review of the progression of microstructured polymer fibres, through the essentially mature field of PCF to the current areas of interest in terahertz waveguides and metamaterials fabrication. The paper is organised as follows. Section 2 will outline the materials used and highlight the properties that make their use appropriate. Section 3 will outline the fabrication methods; the materials and fabrication methods are mostly common to the three areas of research. Sections 4, 5, and 6 will then focus on the individual research areas of microstructured polymer optical fibres, terahertz waveguides, and drawn metamaterials, giving an overview of the research to date in each area. This will be followed by a conclusion in Section 7, where the future directions of this work will be outlined.

\section{Materials}

Conventional (step-index or graded-index) plastic optical fibres (POFs) are based on polymethylmethacrylate (PMMA). It is widely available, inexpensive and has a low loss in the visible, typically quoted as $0.15 \mathrm{~dB} / \mathrm{m}$ at $650 \mathrm{~nm}$ [10]; a summary of the properties of PMMA and other selected polymers is presented in Table 1 and Figure 1. Commercially available POF products are typically highly multimode optical fibres with a $1 \mathrm{~mm}$ core diameter, targeting short distance data transmission, and illumination applications. Several suppliers of such fibres exist including Mitsubishi Rayon (ESKA product line) [33], Optimedia (GigaOptics) [34], and Luceat (LiteWire) [35]. Given PMMA's established use in optical fibres and the consequent availability of optical grade material, the first microstructured polymer optical fibres were also made from PMMA [1]. The first mPOF demonstrated single-mode operation in the visible using the endlessly single-mode PCF design [36] and was the first such demonstration of a single-mode PCF in a material other than silica.

PMMA remains in extensive use for work in microstructured polymer fibres, but as the scope of the work broadened, other commercially available polymers began to be used so as to take advantage of their specific properties (Table 1). Polycarbonate (PC), polystyrene (PS), and polyvinyl difluoride (PVDF) have been used for their refractive index. PC and PS have higher indices approaching 1.6 [10], and PVDF has a lower index of 1.4 [37] compared to PMMA which has an index of 1.49 [10]. PC also has a higher glass transition temperature $\left(T_{g}\right)$ than that of PMMA [38], $150^{\circ} \mathrm{C}$ compared to $115^{\circ} \mathrm{C}$. PMMA, PC, and PS also have comparable material absorption in the visible as shown in Figure 1(a) $[5,39,40]$, although PC is known to degrade in high temperature humid environments [10,38]. The cyclo-olefin polymers/copolymers Zeonex [41, 42] and Topas [43, 44] have also been used, presenting an index between that of PMMA and PC/PS of around 1.53 and virtually no moisture absorption $[42,44]$. 
TABLE 1: Summary of selected polymers used in microstructured polymer fibre fabrication.

\begin{tabular}{|c|c|c|c|c|}
\hline Polymer & Refractive index & Absorption & $T_{g}\left({ }^{\circ} \mathrm{C}\right)$ & Comments \\
\hline Polymethylmethacrylate (PMMA) & $\begin{array}{l}1.49(650 \mathrm{~nm})[10] \\
1.60(1 \mathrm{THz})[19]\end{array}$ & $\begin{array}{c}0.15 \mathrm{~dB} / \mathrm{m}(650 \mathrm{~nm})[5] \\
60 \mathrm{~dB} / \mathrm{cm} \text { or } 14 \mathrm{~cm}^{-1}(1 \mathrm{THz})[19]\end{array}$ & $115[38]$ & $\begin{array}{l}\text { Most widespread } \\
\text { optical polymer }\end{array}$ \\
\hline Polycarbonate (PC) & $\begin{array}{l}1.58(650 \mathrm{~nm})[10] \\
1.65(1 \mathrm{THz})[19]\end{array}$ & $\begin{array}{c}\sim 0.5 \mathrm{~dB} / \mathrm{m}(650 \mathrm{~nm})[39] \\
50 \mathrm{~dB} / \mathrm{cm} \text { or } 12 \mathrm{~cm}^{-1}(1 \mathrm{THz})[19]\end{array}$ & $150[38]$ & $\begin{array}{l}\text { High index and high } \\
T_{g}\end{array}$ \\
\hline Polystyrene (PS) & $1.59(650 \mathrm{~nm})[10]$ & $0.11 \mathrm{~dB} / \mathrm{m}(670 \mathrm{~nm})[40]$ & $100[10]$ & High index \\
\hline Polyvinyl difluoride (PVDF) & $1.40(1050 \mathrm{~nm})[37]$ & & $\begin{array}{l}-30 \\
{[37]}\end{array}$ & Low index \\
\hline $\begin{array}{l}\text { Cyclo-olefin polymer } \\
\text { Zeonex 480R }\end{array}$ & $\begin{array}{l}1.53(650 \mathrm{~nm})[42] \\
1.52(1 \mathrm{THz})[47]\end{array}$ & $0.9 \mathrm{~dB} / \mathrm{cm}$ or $0.2 \mathrm{~cm}^{-1}(1 \mathrm{THz})[47]$ & $138[42]$ & $\begin{array}{l}\text { Transparent for } \mathrm{THz} \text {, } \\
\text { low water absorption }\end{array}$ \\
\hline $\begin{array}{l}\text { Cyclo-olefin copolymer } \\
\text { Topas }\end{array}$ & $\begin{array}{l}1.53(650 \mathrm{~nm})[44] \\
1.52(1 \mathrm{THz})[48]\end{array}$ & $0.9 \mathrm{~dB} / \mathrm{cm}$ or $0.2 \mathrm{~cm}^{-1}(1 \mathrm{THz})[48]$ & $80[44]$ & $\begin{array}{l}\text { Transparent for } \mathrm{THz} \text {, } \\
\text { low water absorption }\end{array}$ \\
\hline Polytetrafluoroethylene (PTFE) & $\begin{array}{l}1.38 \text { (visible) }[19] \\
1.45(1 \mathrm{THz})[19]\end{array}$ & $\begin{array}{c}9 \mathrm{~dB} / \mathrm{cm} \text { or } 2 \mathrm{~cm}^{-1}[19], \text { also } \\
\sim 1.3 \mathrm{~dB} / \mathrm{cm} \text { or } \sim 0.3 \mathrm{~cm}^{-1}[18,45](1 \mathrm{THz})^{*}\end{array}$ & $160-240$ & $\begin{array}{l}\text { For use at } \mathrm{THz} \\
\text { frequencies }\end{array}$ \\
\hline High density polyethylene (HDPE) & $\begin{array}{l}1.54 \text { (visible) [19] } \\
1.53(1 \mathrm{THz})[19]\end{array}$ & $\begin{array}{l}9 \mathrm{~dB} / \mathrm{cm} \text { or } 2 \mathrm{~cm}^{-1}[19], \text { also } \sim 1.3 \mathrm{~dB} / \mathrm{cm} \\
\quad \text { or } \sim 0.3 \mathrm{~cm}^{-1}[18,46](1 \mathrm{THz})^{*}\end{array}$ & -135 & $\begin{array}{l}\text { For use at } \mathrm{THz} \\
\text { frequencies }\end{array}$ \\
\hline Deuterated PMMA (PMMA-d8) & & $60 \mathrm{~dB} / \mathrm{km}(650 \mathrm{~nm})[53]$ & & Deuterated material \\
\hline $\begin{array}{l}\text { Cyclic transparent optical polymer } \\
\text { (CYTOP) }\end{array}$ & $\begin{array}{l}1.34 \text { (visible) [51] } \\
1.35(1 \mathrm{THz})[52]\end{array}$ & $\begin{array}{c}40 \mathrm{~dB} / \mathrm{km}(650 \mathrm{~nm}), 16 \mathrm{~dB} / \mathrm{km}(850 \mathrm{~nm}) \\
20 \mathrm{~dB} / \mathrm{km}(1300 \mathrm{~nm})[49] \\
4 \mathrm{~dB} / \mathrm{cm} \text { or } 1 \mathrm{~cm}^{-1}(1 \mathrm{THz})[52]\end{array}$ & $108[51]$ & Fluorinated material \\
\hline
\end{tabular}

At terahertz frequencies, PMMA has a rather low transparency and is outperformed by many other polymers. Polytetrafluoroethylene (PTFE/Teflon) $[19,45]$, high density polyethylene (HDPE) [19, 46], Zeonex [47], and Topas [48] have losses of one to two orders of magnitude lower than PMMA, as shown in Figure 1(c). In some cases such as PTFE and HDPE, widely varying values of loss have been reported in the literature as is seen in Table 1, most likely attributed to different grades of the polymer, but also possibly influenced by the details of the measurement.

In addition to the commercially available polymers mentioned previously, other proprietary, customised, or novel polymers have also been investigated. The use of cyclic transparent optical polymer (CYTOP) was demonstrated in an optical fibre context $[10,49-51]$ and also at terahertz frequencies in a photonic crystal planar waveguide [52]. CYTOP is a perfluorinated polymer, meaning all the hydrogen in the polymer is replaced by fluorine. The heavier fluorine atoms reduce the frequency of molecular vibrations and shift the associated absorption lines to longer wavelengths, increasing the transparency in the visible and near infrared [49]. A similar increase in transparency can be achieved by replacing the hydrogen atoms with deuterium, as in deuterated PMMA (PMMA-d8) [10, 53]. A comparison of PMMA, PMMA-d8, and CYTOP is presented in Figure 1(b). Whilst PMMA-d8 and CYTOP offer an advantage at $650 \mathrm{~nm}$, the improvement in the infrared is far more striking, with the loss of CYTOP being three orders of magnitude lower than PMMA. This allows CYTOP fibres to operate at the $850 \mathrm{~nm}$ and $1300 \mathrm{~nm}$ telecommunications windows, and thus be compatible with components developed for silica-based systems [49]. Theoretical loss values for fluorinated polymers are an order of magnitude lower than shown in Figure 1(b) and are comparable to the loss of silica glass; however, such low values have never been achieved for a variety of reasons, including difficulties in ensuring an amorphous structure [10] (e.g., PTFE is polycrystalline, resulting in high scattering losses in the visible and a white opaque appearance). The performance of CYTOP at terahertz frequencies is also good, as seen in Figure 1(c).

Despite the real and potential advantages, fluorinated and deuterated polymers are proprietary and/or expensive and difficult to manufacture, so their use has been limited. Materials such as CYTOP have the potential to make the use of $\mathrm{mPOF}$ much more widespread through reducing the loss to allow longer lengths of fibre to be used and through allowing operation in the infrared and compatibility with telecommunications components.

Several demonstrations with novel polymers have also been reported. These include chiral polymers using a copolymer of methyl methacrylate, from which PMMA is derived, and (-)-menthyl methacrylate derived from (-)-menthol, a chiral compound [54]. The availability of chiral material, and hence optical activity (circular birefringence), adds an interesting new dimension to optical waveguides [55]. The use of cellulose for a biodegradable fibre [56] was also demonstrated with potential biomedical applications.

Doping offers an additional route to modifying the polymer. Doping can be achieved by using solvents to swell the polymer and allow the dopant to diffuse into it [57]. 


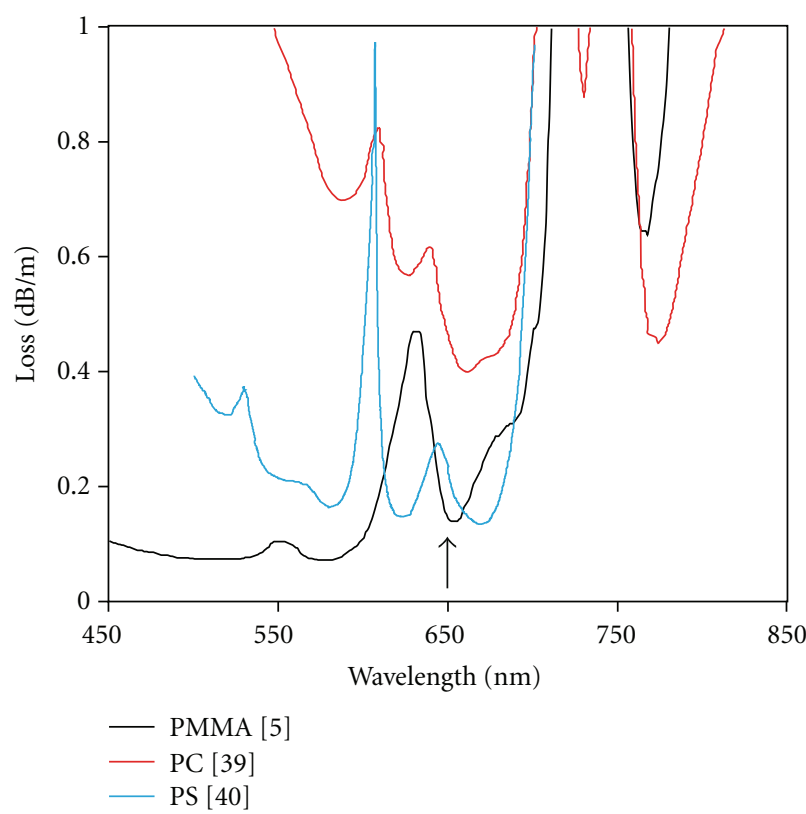

(a)

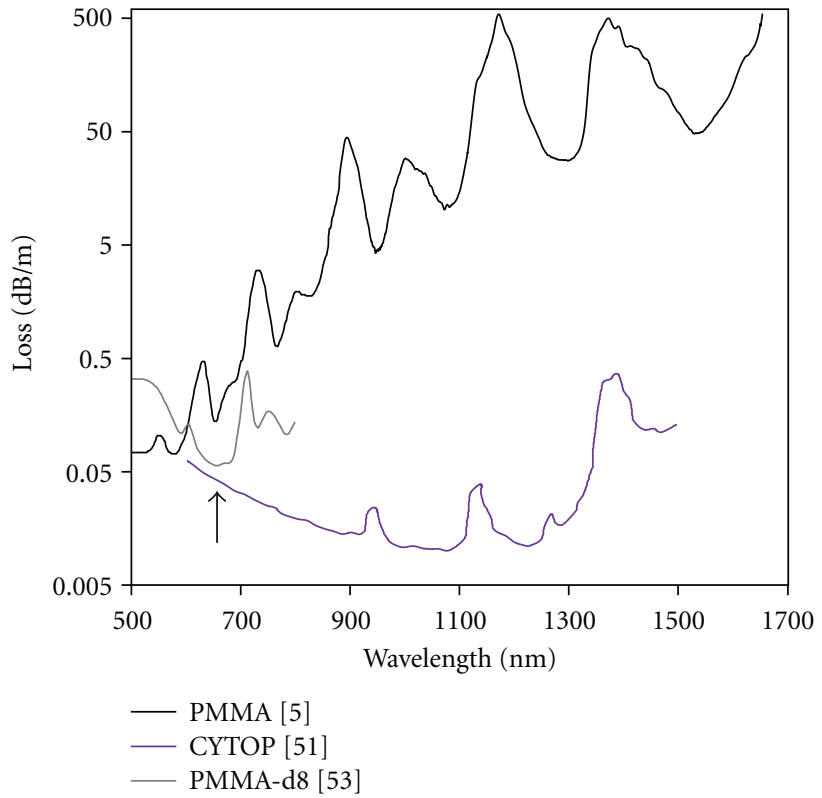

(b)

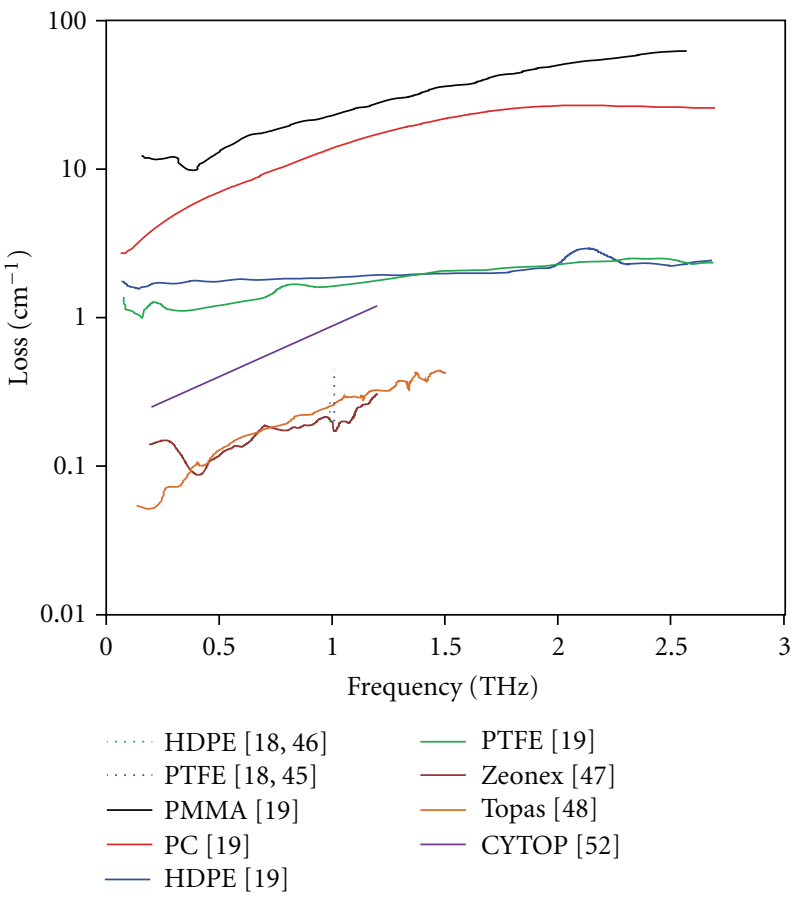

(c)

FiguRE 1: Loss of common polymers used for microstructured polymer fibres in the (a) visible, (b) near infrared, and (c) THz frequency parts of the spectrum; data were extracted from references as shown. The different values given for HDPE and PTFE in (c) are attributed to different grades of polymer. The standard POF operation wavelength of $650 \mathrm{~nm}$ is indicated in (a) and (b). The low loss of PMMA at short wavelengths in (a) may be misleading, as those wavelengths are susceptible to scattering losses, as seen in Figure 8 .

Alternatively, the dopant may be added at the monomer phase prior to polymerisation $[58,59]$. Particulate dopants such as doped nanoparticles [60], magnetic nanoparticles [61], and quantum dots $[60,62,63]$ can be incorporated by dry mixing of the dopants and the polymer in powder form, and then consolidation under pressure at higher temperature (e.g., as would occur in an extrusion process). The lower processing temperature of polymers allows dopants such as quantum dots and organic molecules to survive the draw process without degrading. 


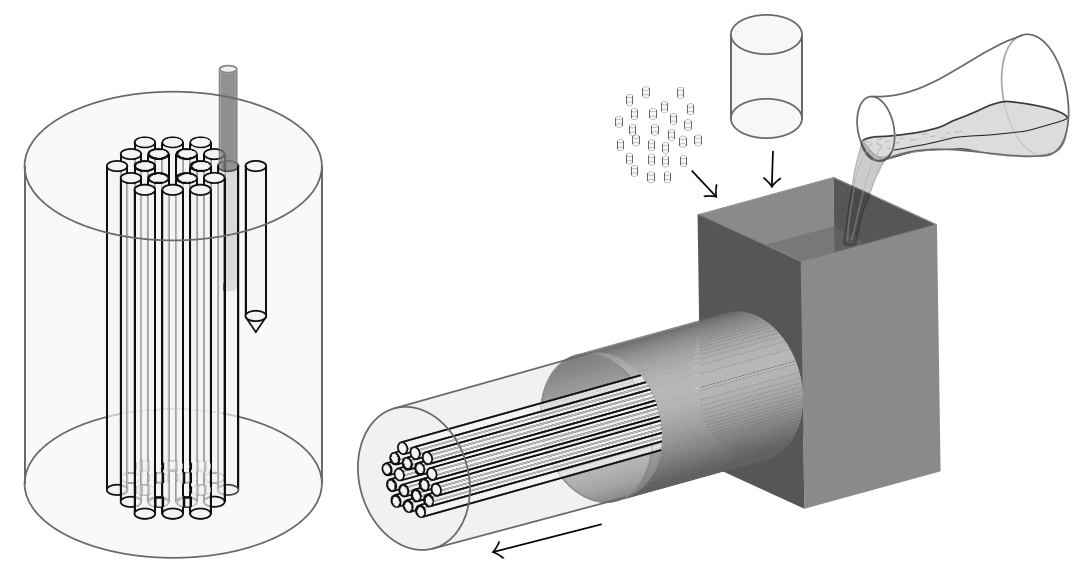

(a)

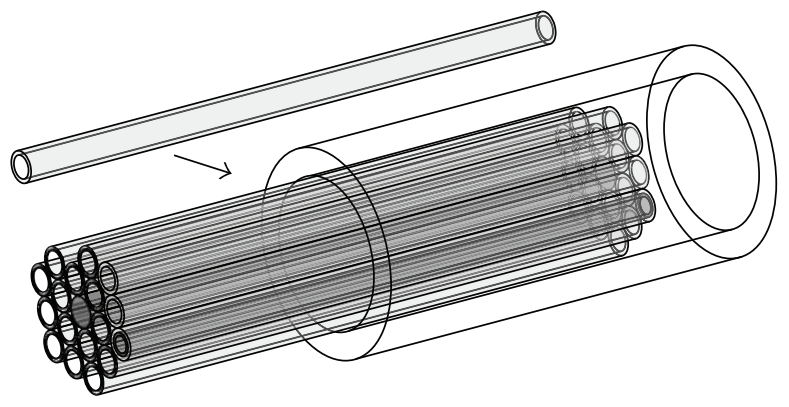

(d) (b)

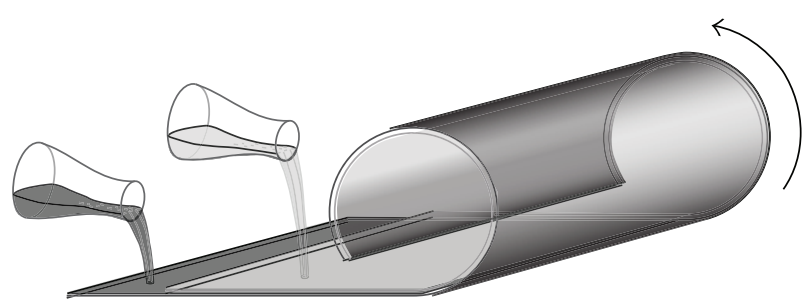

(e)

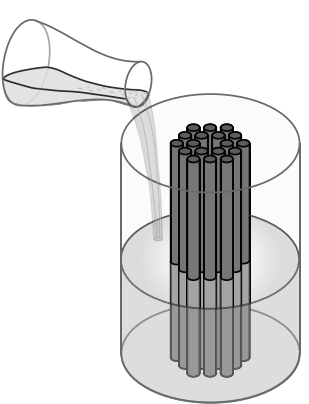

(c)

FIGURE 2: Fabrication methods for microstructured polymer preforms, showing: (a) drilling, (b) extrusion from resin, billets, or monomer, (c) casting/molding, (d) stacking, and (e) rolling of a planar stack constructed using solvent deposition.

As a final note on the materials, it should be explicitly stated that the criterion any polymer must satisfy for use in microstructured fibres is compatibility with the fibre drawing process. This places constraints on the molecular weight, polydispersity, degree of cross-linking, and level of impurities. Too high degree of cross-linking or molecular weights that are too large will prevent the polymer chains from sliding past each other and will make the polymer rubbery upon heating, preventing it from being stretched to fibre. Any volatile impurities such as remnant monomer, initiator, or absorbed moisture may evaporate during the draw process and create bubbles. For PMMA, molecular weights in the range of 50,000 to 100,000 are required, and the polydispersity of material used ranged between 2.0 and 2.3. Volatile impurities may be extracted by annealing the polymers (heating below $T_{g}$, e.g., at $90^{\circ} \mathrm{C}$ for PMMA and Zeonex, or $110^{\circ} \mathrm{C}$ for PC) for a sufficient time of between a few days and a month, depending on size, prior to processing or drawing. Polymers that have already been processed by extrusion are generally compatible with the draw process given the similarity between the two; however, polymers prepared by casting are not always able to be drawn.

\section{Fabrication Methods}

The common element of the work under review here is the fabrication of microstructured polymer fibres by fibre drawing methods. Fibre drawing entails at least two stages of fabrication, beginning with the construction of a preform which is a scaled-up (larger in diameter, shorter in length) version of the fibre that contains its essential features such as the necessary structure and material. The second stage is drawing this preform to fibre using a draw tower. The basic draw process involves heating the preform to a temperature sufficiently larger than $T_{g}$ to reduce its viscosity such that it can be drawn to fibre (e.g., at around $200^{\circ} \mathrm{C}$ for PMMA). The process may also involve intermediate stages, such as drawing the initial preform to an intermediate size called "cane," sleeving to increase diameter, or combining several canes to form a new preform $[5,64]$.

Polymers lend themselves to a wider range of fabrication techniques than silica glass owing to the lower processing temperatures and ease of machining; as a result, a variety of methods have been demonstrated as summarised in Figure 2. The first $\mathrm{mPOF}$ was made from a preform formed by drilling the desired hole structure into a PMMA cylinder $8 \mathrm{~cm}$ in diameter (Figure 2(a)) [1, 65]. Extrusion (Figure 2(b)) [66] and polymerisation/casting of preforms (Figure 2(c)) [59] have also been demonstrated and in common with drilling produce monolithic preforms. The extrusion (and to a lesser extent, casting) may begin with the monomer, resin or a polymer billet. Stacking is shown in Figure 2(d) in which the preform is assembled from rods, tubes or capillaries [67]; incidentally, this is the method used most commonly for 

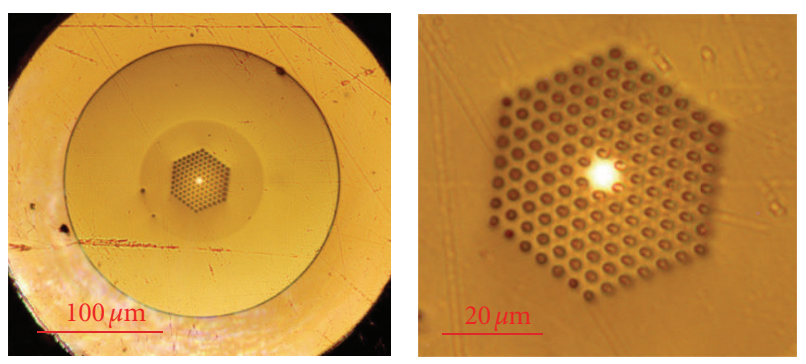

(a)
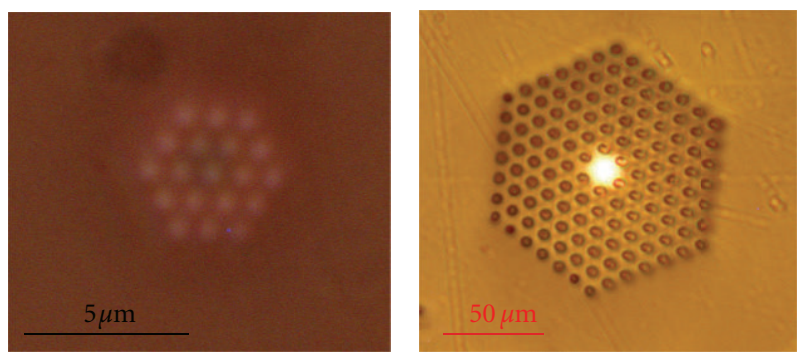

(b)

FIgure 3: (a) A single-mode mPOF made of PMMA for the visible using the hexagonal hole array. The original cane was sleeved twice, firstly with a PMMA jacket and finally with a PC outer jacket. (b) An all-solid single-mode mPOF using a composite core consisting of Zeonex rods in a PMMA background. The right image shows the far field at $650 \mathrm{~nm}$, showing single-mode operation. Figures adapted from (a) [11] and (b) [41].

producing silica PCF [9]. The necessary prefabricated tubes, and rods are assembled into the desired arrangement and placed into a consolidating tube to hold the arrangement securely in place. The advantage of this method, although prone to contamination from the larger surface area of the constituent pieces, is that very large air fractions can be achieved by using very thin-walled tubes. Such air fractions cannot be achieved by the other methods and may be necessary for some fibre designs, such as hollow-core optical fibres [67-69].

These methods (or combinations thereof) are generally versatile, allowing many fibre geometries to be achieved. Their use in isolation (except for stacking) is mostly limited to single-material fibres. Multimaterial fibres are also of interest, requiring these methods to be modified and/or new methods to be employed. Multimaterial optical fibres were initially demonstrated for guiding radiation from $\mathrm{CO}_{2}$ lasers (10.6 $\mu \mathrm{m}$ wavelength), resulting in commercial products for laser surgery called OmniGuide fibres [70]. These consist of a hollow core surrounded by a dielectric stack (a Bragg fibre) made of polyethersulfone and arsenic triselenide. The dielectric stack is initially made in planar form and then rolled into a cylinder to make the preform. This method was also used to make similar Bragg fibres using solvent deposition, as shown in Figure 2(e), and a combinations of PMMA/PS and $\mathrm{PVDF} / \mathrm{PC}$ were used to maximise the index contrast between the layers of the Bragg reflector [37, 71]. The OmniGuide work was extended to include semiconductors and metals in the fibres, demonstrating fibres (and materials woven from these fibres) that were photosensitive, as well as having other functionalities [72, 73]. Multimaterial microstructured polymer fibres can similarly be made through combinations of the methods noted previously, such as drilling a structure and inserting another material into the holes (Figure 2(a)) [41], stacking different materials or stacking tubes containing different materials (Figure 2(d)) [74]. In particular, this has been used for including metals in the fibres for work in drawn metamaterials [75-77]. In fact, the principle of drawing metals in a dielectric fibre dates back to the Taylor wire process [78].

Once the initial preform is constructed using any of these methods or combinations thereof, the preform can be drawn to fibre, possibly through the intermediate cane stage. Additional processing such as filling holes or increasing the overall diameter through sleeving may be done at this cane stage. An example of sleeving to increase the fibre diameter can be seen in Figure 3(a), where two additional layers of polymer can be seen. During the fibre draw, the microstructure may change due to the interplay between surface tension and viscosity. This can be controlled through the draw temperature, and the speeds with which the preform is fed into the furnace and the fibre is drawn. Variation of these parameters can encourage hole collapse (e.g., hotter draw) or relative hole expansion (e.g., colder draw). The details of the draw process and roles of the material parameters have been well understood through a series of numerical and experimental studies on PMMA (and silica) fibres [79-83]. Pressure and/or vacuum may also be used to control the microstructure during drawing.

\section{Microstructured Polymer Optical Fibres}

A large fraction of the work on silica PCF focused on nonlinear optics. The unprecedented control of dispersion and the high degree of confinement that could be achieved led to a very successful study of nonlinear optics in fibres with enhanced nonlinearity $[9,84]$. On the other hand, the ability to fabricate large mode area single-mode fibres with very low nonlinearity allowed higher power operation without encountering nonlinear effects or damaging the fibres [85-87]. These investigations led to two commercial outcomes of PCF-supercontinuum sources and fibre lasers. The initial interest in $\mathrm{mPOF}$ was inspired by the work in silica PCF, and the investigations into MPOF began with the aim of seeing what could be achieved from the combination of microstructure and polymers. Similar work into fibre dispersion, nonlinear optics, or high power fibre lasers was not possible owing to the lower damage threshold of PMMA and the higher loss, which prevented the use of high powers and long interaction lengths. The only exceptions to this were demonstrations of mPOF fibre lasers based on organic dyes and the observation of stimulated Raman scattering in PMMA fibres [58, 88, 89]. This section will focus on three main outcomes of $\mathrm{mPOF}$ research, namely the ability to make single-mode fibres for the visible and the gratings-based sensing approaches that enables, high-bandwidth multimode fibres, and mPOF used for liquid-based sensing. Finally, 
other novel fibres directed in part towards understanding the physics of microstructured fibres will also be discussed.

4.1. Single-Mode Polymer Fibres and Gratings-Based Sensing. Although single-mode fibres are ubiquitous when dealing with silica, the POF world is dominated by large $1 \mathrm{~mm}$ core multimode fibres estimated to support of order $10^{7}$ modes at $650 \mathrm{~nm}[10,33-35]$. Single-mode mPOF have been reported since the first mPOF paper of 2001 [1], using the familiar hexagonal array of holes that is almost synonymous with PCF. More recently, an all-solid version was reported in which the core consisted of a sparse array of subwavelength Zeonex rods (index of 1.53), giving the core an average index slightly above the PMMA background (index of 1.49) [41]. Examples of these single-mode fibres are shown in Figure 3.

A single-mode plastic fibre is of no interest for communications, given the relatively high attenuation of PMMA and the resulting short-distance data links it implies. Having single-mode (and also few-moded) fibres does have important outcomes, however, including the possibility of inscribing gratings $[90,91]$. It is in this context of gratings that the different material properties found in polymers can be most effectively utilised. A summary of the relevant properties of PMMA compared to silica is presented in Table 2. Gratings turn single-mode mPOF into sensors with thermal, humidity, and strain responses. PMMA has an elastic limit of $4 \%-10 \%$, a breaking strain beyond $20 \%$, and a thermo-optic coefficient of $-1.1 \times 10^{-4}$ [4]. The most striking advantage over silica fibres is the ability to achieve large strains (see inset of Figure 4(a)).

Work into long period gratings (LPG) in PMMA singlemode $\mathrm{MPOF}$ has resulted from these differences in material properties. LPGs can be easily inscribed by physical imprinting with a pitch of order $1 \mathrm{~mm}$ [91], to give resonance features in the 500-750 $\mathrm{nm}$ range where PMMA-based mPOFs are the most transparent, allowing up to $10 \mathrm{~m}$ of fibre to be used. An example of such an LPG spectrum is shown in Figure 4(a). Demonstrations of strain [92-96], humidity [94, 97, 98], temperature [94] and pressure [99] sensing, and biosensing [100] with these LPGs, have been reported. Typical responses observed were $-11 \mathrm{~nm} / \%$ strain, $0.5 \mathrm{~nm} / 10 \%$ relative humidity, and $0.2 \mathrm{~nm} /{ }^{\circ} \mathrm{C}$ [92-98], as shown in Table 3.

One particularly interesting use of MPOF LPG is the demonstration of a heart rate sensor [101]; the response of the LPG is sensitive enough to detect a person's heart beat when the fibre is placed around the torso. This has potential applications in personal protective equipment and medical settings in which metallic components cannot be used. The biocompatibility of PMMA is an additional advantage in this case.

In addition to LPG, fibre Bragg gratings (FBGs) have also been demonstrated in single-mode and smaller core multimode mPOF [90]. This work has been carried out at telecommunications wavelengths (dictated by silica-oriented FBG inscription techniques), using PMMA [90, 102-106] and Topas fibres [106-108]. Such wavelengths are not particularly favourable due to the material loss restricting fibre lengths to approximately $10 \mathrm{~cm}$ (see Figure 1(b)), requiring interfacing
TABLE 2: Comparison of PMMA and silica material properties.

\begin{tabular}{lcc}
\hline Property & PMMA & Silica \\
\hline Young's modulus & $3.2 \mathrm{GPa}$ & $72 \mathrm{GPa}$ \\
Elastic limit & $<10 \%$ & $\sim 1 \%$ \\
Thermal expansion coefficient & $9 \times 10^{-5}$ & $5.5 \times 10^{-7}$ \\
Thermo-optic coefficient & $-1.1 \times 10^{-4}$ & $9.2 \times 10^{-6}$ \\
\hline
\end{tabular}

Data were taken from [4].

with silica fibres for characterisation. More recently, FBGs with wavelengths approaching $800 \mathrm{~nm}$ have been reported $[102,107]$, aiming to move towards the transparency windows of those polymers. An example of such an FBG inscribed in a multimode PMMA fibre is shown in Figure 4(b). These gratings have similarly been characterised for strain, humidity, and temperature sensing, with typical responses as shown in Table 3. In particular, Topas FBGs were demonstrated to be insensitive to humidity, given the negligible water absorption of Topas [107], shown in Figure 4(d).

The comparison between FBG and LPG and polymer and silica combinations in Table 3 shows that mPOF LPGs have the largest response to all three stimuli considered, in addition to the advantage of operating in the visible in the transparency window of the polymers. The loss of the fibres is $<2 \mathrm{~dB} / \mathrm{m}$ (discussed in Section 4.5 and Figure 8), the temperature response is 2.5 to 5 larger than all the other options, and the humidity response is larger compared to PMMA POF FBG, but can be eliminated with the use of Topas. Furthermore, the strain response for FBG is proportional to the wavelength of the grating. Scaling the FBG results to the visible gives an estimated response of $5 \mathrm{~nm} / \%$, which is less than half of reported values for LPG.

A comparison reported in [109] showed that the strain response of $\mathrm{mPOF}$ FBG is identical to step-index POF FBG, as seen in Figure 4(c). This is to be expected given PMMA was used in both cases. An important difference, however, is that the few-moded step-index POF in [109] had losses approaching $550 \mathrm{~dB} / \mathrm{m}$ at $700 \mathrm{~nm}$, compared of $<2 \mathrm{~dB} / \mathrm{m}$ for the single-mode mPOF. Compared to silica FBG $[110,111]$, the polymer FBGs have the same strain response, but with a much larger elastic limit of $\sim 4 \%$ and maximum strain exceeding $20 \%$. Polymer FBGs also have a temperature response that is 3-4 times larger and in the opposite direction compared to silica. This is attributed to a larger and negative thermooptic coefficient (Table 2). It should be noted that the strain response is dominated by changes to the grating pitch, whereas temperature response is dominated by the thermooptic coefficient, and humidity response by the material absorbing water and changing refractive index as a result. Silica fibres nominally have no humidity response.

The potential sensing applications of $\mathrm{mPOF}$ gratings are still being investigated, whether for FBG or LPG. The large strains possible, larger temperature and humidity responses, and the biocompatibility of polymers will be important advantages in any future applications. Requirements of any particular deployment will also contribute to the choice between characterisations of the fibre in transmission, which 
TABLE 3: Comparison of mPOF, POF, and silica LPG and FBG responses.

\begin{tabular}{|c|c|c|c|}
\hline Grating type & $\begin{array}{l}\text { Strain response } \\
\quad(\mathrm{nm} / \%)\end{array}$ & $\begin{array}{c}\text { Temperature } \\
\text { response } \\
\left(\mathrm{nm} /{ }^{\circ} \mathrm{C}\right)\end{array}$ & $\begin{array}{l}\text { Humidity } \\
\text { response } \\
(\mathrm{nm} / 10 \%)\end{array}$ \\
\hline $\begin{array}{l}\text { mPOF LPG PMMA } \\
\text { (vis) }\end{array}$ & $\begin{array}{l}-11[92-94] \\
-5.4[95]\end{array}$ & $0.2[96]$ & 0.5 [97] \\
\hline $\begin{array}{l}\text { mPOF FBG PMMA } \\
(\sim 1550 \mathrm{~nm})\end{array}$ & $13[105,109]$ & $\begin{array}{l}-0.08^{*}[102] \\
-0.05^{\#}[102]\end{array}$ & \\
\hline $\begin{array}{l}\text { mPOF FBG PMMA } \\
(\sim 800 \mathrm{~nm})\end{array}$ & $7.1[103,109]$ & & \\
\hline $\begin{array}{l}\text { mPOF FBG Topas } \\
(\sim 1550 \mathrm{~nm})\end{array}$ & & $-0.04[108]$ & $0.006[107]$ \\
\hline $\begin{array}{l}\text { mPOF FBG Topas } \\
(\sim 800 \mathrm{~nm})\end{array}$ & 6.4 [107] & $-0.08[107]$ & $<0.007^{\wedge}[107]$ \\
\hline $\begin{array}{l}\text { POF FBG PMMA } \\
(\sim 1550 \mathrm{~nm})\end{array}$ & 13 [109] & $-0.055[110]$ & $0.35[110]$ \\
\hline $\begin{array}{l}\text { POF FBG PMMA } \\
(\sim 800 \mathrm{~nm})\end{array}$ & 7.1 [109] & & \\
\hline $\begin{array}{l}\text { Silica FBG } \\
(\sim 1550 \mathrm{~nm})\end{array}$ & $13[111]$ & $0.014[110,111]$ & $0.0028^{\sim}[110]$ \\
\hline
\end{tabular}

Data taken or inferred from references as indicated. ${ }^{*}$ For unannealed fibre. ${ }^{\#}$ For annealed fibre. ${ }^{\wedge}$ Worst case scenario, real value likely to be much lower. ${ }^{\sim}$ Likely due to the polymer coating on the silica fibre, not the silica itself. Note that the response may also depend on the details of the fibre structure.

is compatible with both FBG and LPG, or in reflection which is compatible with FBG only.

4.2. High-Bandwidth Fibres. Another outcome of mPOF research was high-bandwidth $\mathrm{mPOF}$, which arose from initial investigations into the main application of conventional POF: short-range data transmission using $650 \mathrm{~nm}$ light over lengths up to $100 \mathrm{~m}$ [10]. Although complex structures were initially sought to achieve an azimuthally averaged graded profile (e.g., hole radii and/or filling fraction increasing outwards from the centre of the core) [112], it was eventually realised that a single ring of holes was all that was required to achieve high data rates $[12,13]$. This has produced multimode mPOF with approximately $150 \mu \mathrm{m}$ core diameters and $500 \mu \mathrm{m}$ outer diameters that have achieved $9.5 \mathrm{~Gb} / \mathrm{s}$ data rates using on-off keying and a relatively complex light source based on telecommunications sources in the infrared and four-wave mixing to convert the signal to the visible [12], as well as $7.3 \mathrm{~Gb} / \mathrm{s}$ using inexpensive laser diodes in combination with a more complex modulation format (discrete multitone modulation, DMT) [13], both over $50 \mathrm{~m}$. Examples of the fibre structure and data transmission measurements are shown in Figure 5. These data rates are compared to the $100 \mathrm{Mb} / \mathrm{s}$ to $1 \mathrm{~Gb} / \mathrm{s}$ data rates typical of conventional polymer step- and graded-index fibres targeting fibre-to-the-premises and fibrein-the-premises applications. Comparable data rates have been achieved over conventional fibres but have required additional complexity in the system. For example, $10 \mathrm{~Gb} / \mathrm{s}$ was achieved only over $35 \mathrm{~m}$ using a graded-index POF using DMT and a specialised receiver [113], whilst measurements over $50 \mathrm{~m}$ were limited to $6 \mathrm{~Gb} / \mathrm{s}$ and required complex equalisation circuits [114].

The fact that these fibres are multimode and yet achieve such high data rates indicates that the microstructure is responsible for reducing the modal dispersion. Earlier studies into these fibres observed that the bandwidth-length product was not constant, indicating that the modal dispersion was not resulting in pulse spreading as expected, but in fact, the width of pulses propagating in the fibre approached a constant value after certain propagation lengths, about $40 \mathrm{~m}$ in that case [115]. This suggests the presence of a small group of modes with low modal dispersion and low loss that are observed after long lengths of fibre and a second group of higher order, higher loss modes that result in pulse spreading over shorter length scales, but do not survive to the longer lengths. Such a description in terms of two mode groups is consistent with observed bending loss behaviour for similar fibres [116]. Higher bend loss was observed for short bent lengths of fibre (when the higher order modes are being lost), with the bend loss reducing for longer bent lengths (where the lower order, lower loss modes remain). The use of polymer allows the large diameters to be achieved in a flexible fibre, which are important for the targeted applications such as fibre-in-the-premises, where easy handling and low connector costs are essential [10].

4.3. Liquid-Based Sensing. Apart from the grating-based sensing discussed previously, another body of work on mPOF has focused on liquid-based sensing. In many of these cases, the compatibility of the polymer with various fabrication 


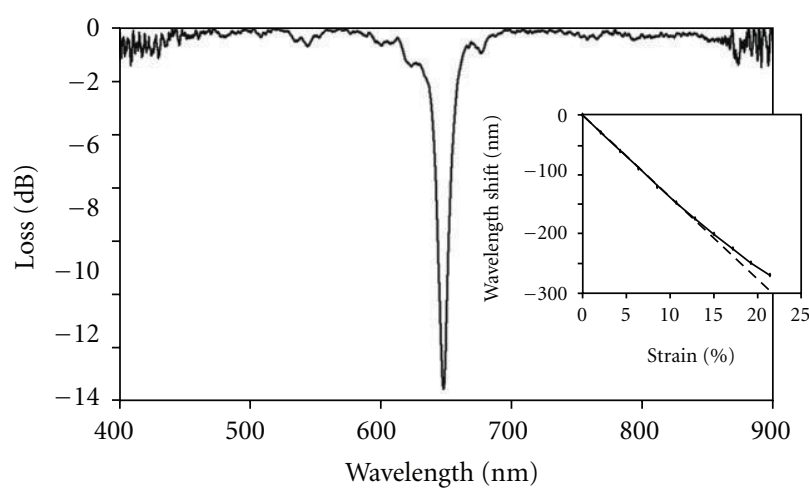

(a)

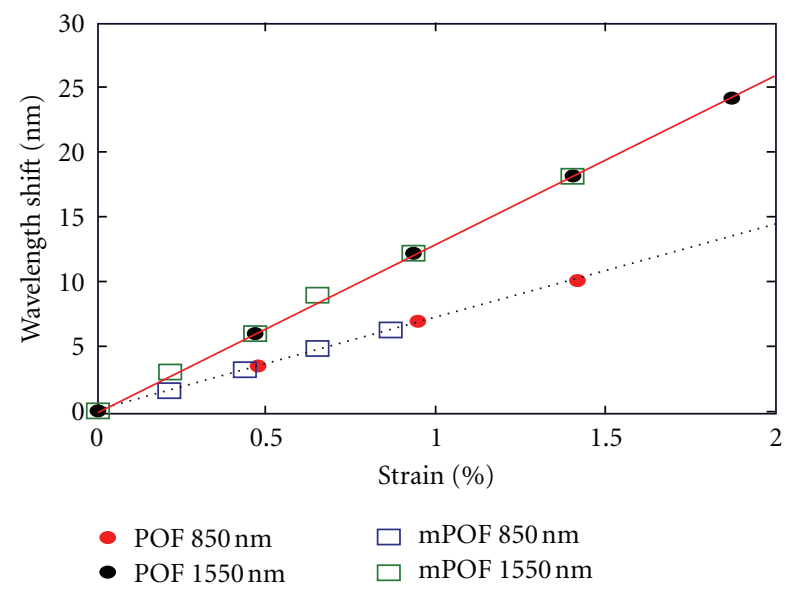

(c)

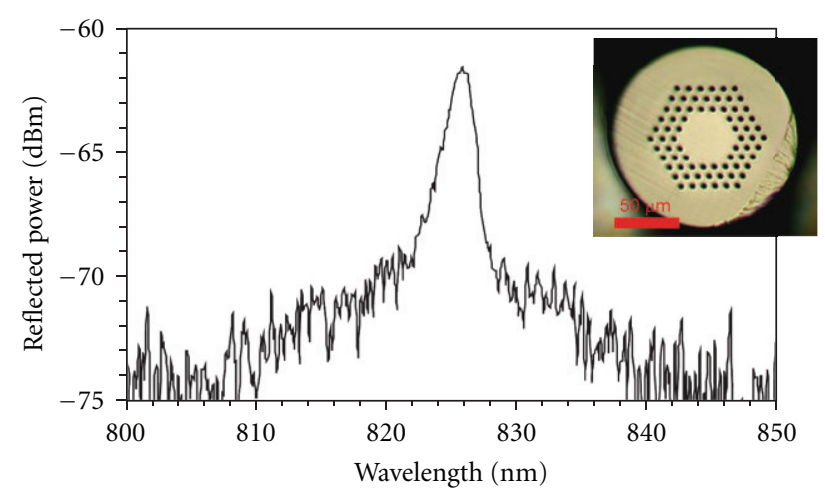

(b)

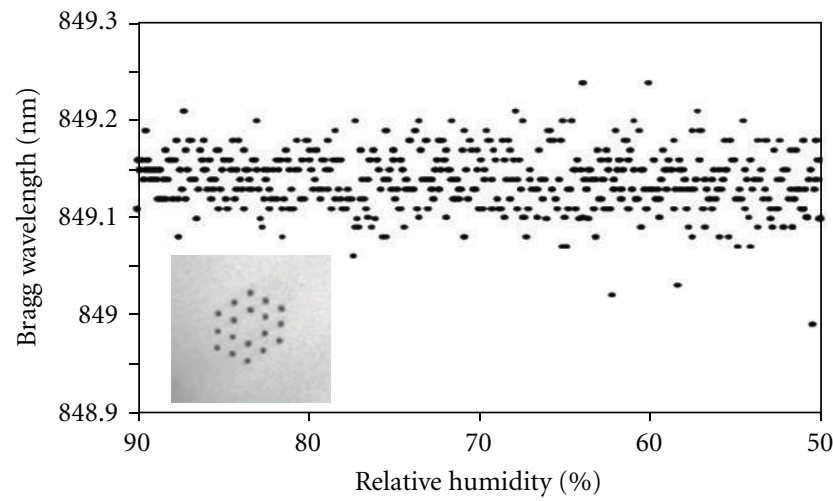

(d)

Figure 4: (a) Transmission spectrum of an LPG in a single-mode mPOF similar to Figure 3(a). Inset shows strain response up to strains exceeding 20\%. (b) Reflection spectrum of an FBG in a multimode mPOF with a $50 \mu \mathrm{m}$ core diameter, with fibre cross-section in inset. (c) Comparison of strain response for FBG inscribed in $\mathrm{mPOF}$ and step-index POF. (d) Humidity response of a FBG inscribed in a Topas mPOF, with fibre cross-section in inset. Adapted from (a) [93, 96], (b) [103], (c) [109], and (d) [107].

methods and/or chemical processes has enabled this work. The theme here (and of optical fibre sensors in general) is to increase the overlap between the guided mode of the fibre and the material to be sensed. This has been approached through various fibre geometries, creating structures where both the light and material are in the same place, and through chemical approaches that result in an increased interaction.

A notable example of using the chemical approach is coating the holes of a Topas mPOF with a binding agent to selectively bind a particular antibody to the hole surface [43]. Although the light is confined to the core, there are evanescent fields in the holes, and these are the strongest at the hole surface at the edge of the core, where the antibodies would now be bound. This enhances the interaction of only that particular antibody with the evanescent field of the guided mode and results in enhanced selective detection as seen in Figure 6(a). Other examples include modifying the inner surface of PMMA mPOF with a titanium oxide film to sensitise the fibres to hydrogen peroxide [117], and with cellulose to sensitise them to nitrites [118]. A structure-based approached was to add holes to the core itself and create more opportunities for overlap of the light and material filling the holes, as seen in Figure 6(b) [119].

The previous examples required the holes of the fibre to be filled in order for the sensor to work. Side trenches in the fibre and an exposed core, as in Figure 6(c), remove this requirement and allow the fibre to sense the environment in which it is immersed [120]. The exposed core could also be coated with gold to allow for sensing through surface plasmons [121]. Metallic coatings on the inside of the holes have also been reported, to increase the interaction between the metal and the light and any material filling the holes [122]. Such coatings can increase phenomena like surface-enhanced Raman scattering. (Interest in using metal in the fibre for the fabrication of metamaterials is a separate topic covered in Section 6.)

Finally, the possibility of making hollow-core mPOF (HC-mPOF) allows the material to be placed in the core itself, completely overlapping with the propagating light. Demonstrations of filling the core with a chiral solution and measuring the resulting optical rotation have been reported [123]. Filling the core with a suspension of nanoparticles 

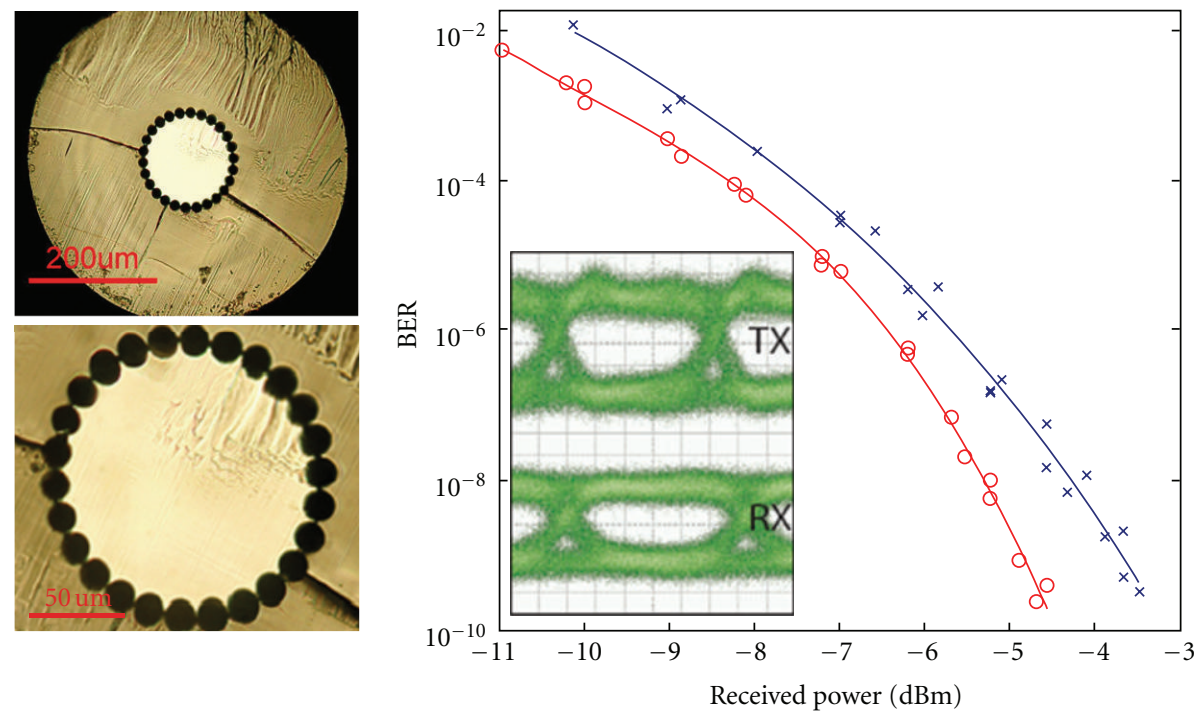

$\times \mathrm{RX}$

O TX (a)
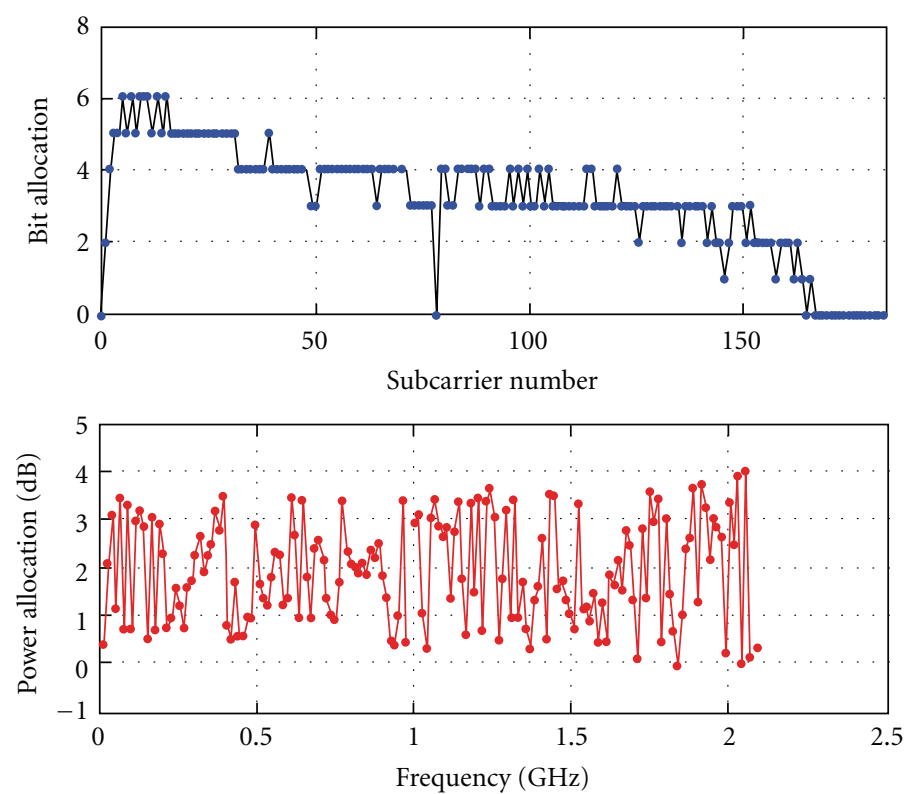

(c)
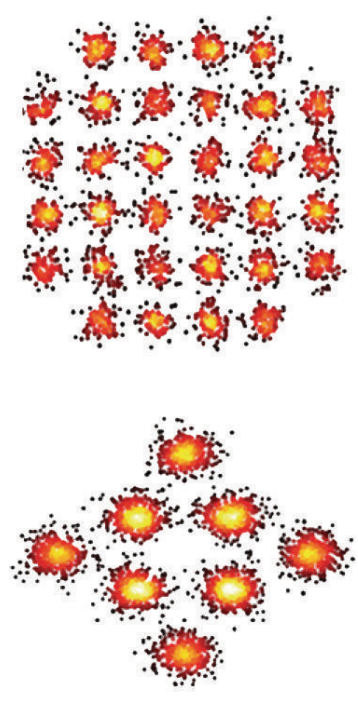

(d)

FIGURE 5: (a) Cross section of a PMMA multimode high-bandwidth mPOF. (b) Bit error rate for 9.5 Gb/s signal at $636 \mathrm{~nm}$ with on-off keying as a function of received power over a $50 \mathrm{~m}$ length of fibre, with inset showing eye diagrams. (c) Bit and power allocation using a $650 \mathrm{~nm}$ laser diode and discrete multitone (DMT) modulation, and also over $50 \mathrm{~m}$ of fibre. (d) Constellation diagram of the demodulated signals from (c) showing 32 level quadrature amplitude modulation (QAM) from subcarriers 20-29, and 8-QAM from subcarriers 125-135. Adapted from (a) and (b) [12], (c) and (d) [13].

allowed spectroscopy based on surface-enhanced Raman scattering to be conducted inside the fibre [124]. In this case, the fibre contains the sample and guides both the pump and signal wavelengths to and from the laser source/detector. Finally, individual microparticles were trapped inside the core of a HC-mPOF using an optical trapping beam incident transversely through the fibre cladding. These individual particles could be held in place and interrogated through fluorescence spectroscopy [125]. In this demonstration, the pump beam was incident on the particles transversely through the cladding, and the fluorescence was collected by the fibre core and guided to a detector. The results are shown in Figure 6(d).

In many of these cases, the chemistry and ability to machine the polymer made the investigations possible. The exposed core fibres could be fabricated by machining a trench 

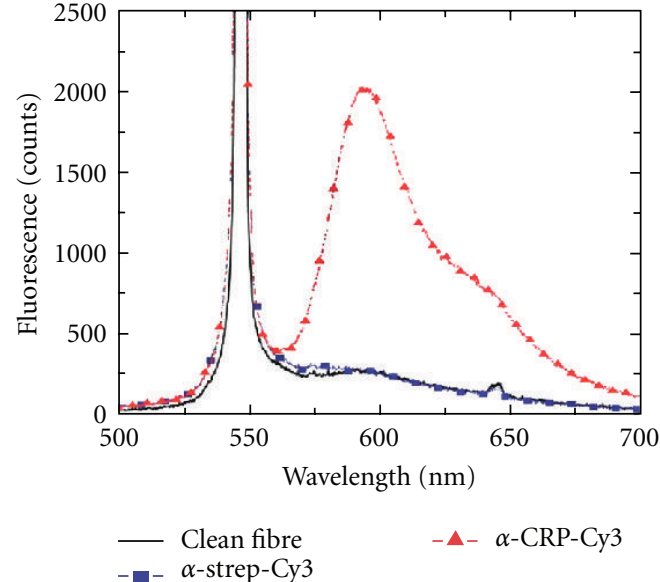

(a)

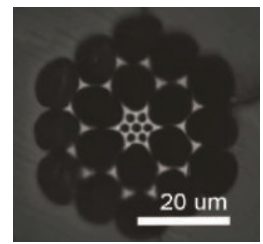

(b)

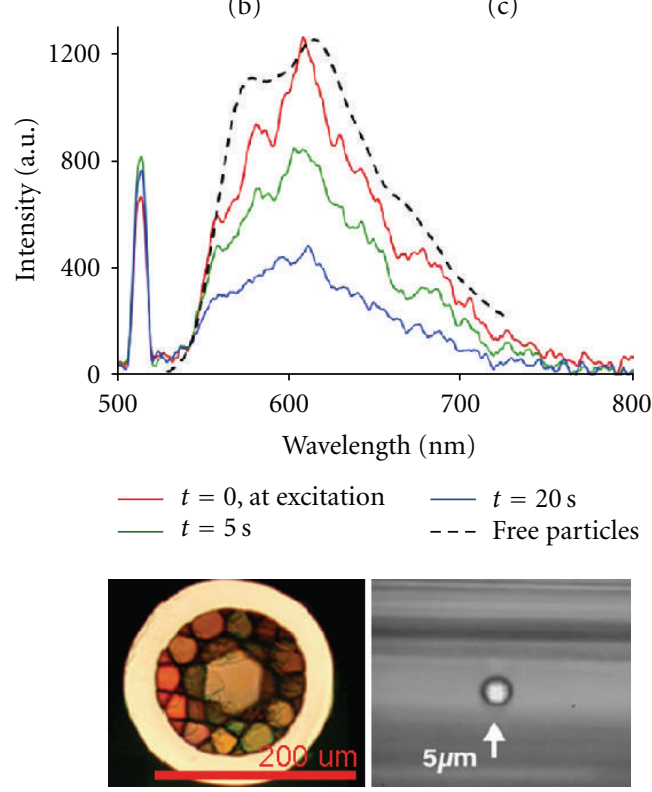

(d)

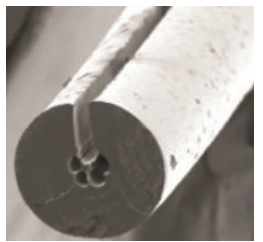

(c) 


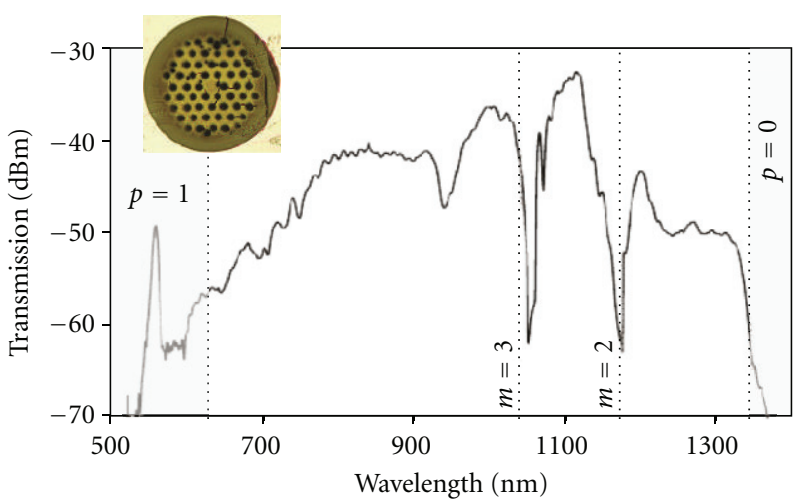

(a)

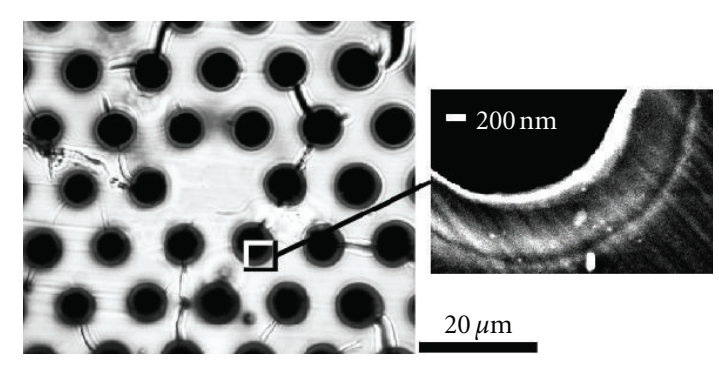

(b)

FIgURE 7: A PMMA fibre with high-index PC rings inside each hole, used to study the inhibited coupling mechanism. (a) Transmission showing a wide transmission window (wavelengths labelled " $p$ " and " $m$ " correspond to expected high loss regions). (b) Image of the fibre showing the PC layers. Adapted from [74].

single-mode hollow-core photonic bandgap fibres will have losses of order $1 \mathrm{~dB} / \mathrm{m}$ in the visible and will guide over a narrow wavelength range. Inhibited coupling fibres will guide over a larger wavelength range, but losses of $0.18 \mathrm{~dB} / \mathrm{m}$ have only recently been reported for silica fibres [134]. Furthermore, defects in the microstructure are detrimental in both hollow-core fibre types. These types of fibres are of particular interest for use at terahertz frequencies, and this comparison will be discussed in more detail in Section 5 .

4.5. Limitations. The limitations of $\mathrm{mPOF}$ arise ultimately from loss and temperature stability (which both compare unfavourably to silica). For the larger core multimode fibres, such as the high-bandwidth fibres, the loss and temperature stability specifications of commercially available conventional POF have been matched [11]. The lowest loss achieved in this case is $0.16 \mathrm{~dB} / \mathrm{m}$ at $650 \mathrm{~nm}$, shown in Figure 8, and the loss is generally $<0.2 \mathrm{~dB} / \mathrm{m}$ at $650 \mathrm{~nm}$. Operation up to $90^{\circ} \mathrm{C}$ can be achieved with losses $<0.24 \mathrm{~dB} / \mathrm{m}$. These limits are determined by the material itself, PMMA, and other loss mechanisms such as microbending, defects, and surface roughness on the inner surface of the holes appear to make negligible contributions in these cases [11]. In addition, bending losses can be greatly reduced [116].

As the core diameter is reduced, the light increasingly interacts with the surface of the holes, and roughness thereon begins to become problematic as it increases the loss through scattering. A very clear dependence of loss on core diameter is seen in Figure 8(a). This results in the loss of the singlemode fibres increasing to $1.6 \mathrm{~dB} / \mathrm{m}$ at $650 \mathrm{~nm}$ and limits the use of such fibre to lengths of around $10 \mathrm{~m}$ as noted earlier. As the diameter of the entire fibre is reduced, the lower Young's modulus of the polymer (Table 2) means that microbending becomes a problem, seen in Figure 8(b). To minimise this, the diameter of fibres must be kept above $250 \mu \mathrm{m}$, whilst microbending is eliminated at $500 \mu \mathrm{m}$ diameters. The silica fibre standard of $125 \mu \mathrm{m}$ is thus highly impractical [11].

There is no clear way to overcome these limitations, especially all of them simultaneously. As noted previously, a material like CYTOP has a significantly lower loss than PMMA, particularly in the infrared, and would result in reducing the loss of the fibres. However, CYTOP has lower temperature stability than PMMA, and materials with higher $T_{g}$ such as PC have a higher loss (see Table 1 and Figure 1). Hollow-core fibres can reduce material loss in the infrared where it is very high, but offer no real advantage in the visible as other loss mechanisms like scattering dominate, as discussed in Section 4.4. It is unclear if the surface roughness problem on the internal surface of the holes is a fabrication issue or an intrinsic property of the polymer (studies of roughness in silica HC-PCF found roughness to have thermodynamic origins in surface capillary waves on the molten glass and thus could not be eliminated [126]). A suitable jacketing material may help with microbending losses, although they are eliminated with a sufficiently thick fibre [11].

\section{THz Waveguides}

The guidance of $\mathrm{THz}$ radiation with a waveguide equivalent to an optical fibre remains an unsolved problem. Several challenges must be managed, beginning with the broader spectrum of $\mathrm{THz}$ radiation that one would want to guide, ideally $\sim 6.5$ octaves of frequency to cover the nominal range of 0.1 to $10 \mathrm{THz}$ compared to $\sim 2.5$ octaves through the visible and near infrared. The larger wavelengths lead towards equivalently larger waveguides which become impractically thick and inflexible. Finally, there has been no sufficiently transparent material identified, meaning absorption losses would also need to be managed. As seen in Table 1 and Figure 1(c), Zeonex and Topas have amongst the lowest losses, but these are nevertheless at the level of $\sim 1 \mathrm{~dB} / \mathrm{cm}$ or $0.2 \mathrm{~cm}^{-1}$ at $1 \mathrm{THz}$. Other transparent materials like highresistivity silicon would be rigid and not compatible with fibre fabrication.

There have been many demonstrations of $\mathrm{THz}$ waveguides based on both metallic microwave waveguides (approaching the problem from lower frequencies) and on dielectric waveguides (optical fibres, approaching from higher frequencies). Metal-based waveguides include metal wires [135], parallel metal plates [136], and metal or metalcoated tubes $[137,138]$ and have reported losses of order 0.01 to $1 \mathrm{~cm}^{-1}$. Dielectric-based waveguides initially relied on total internal reflection at the interface between the 


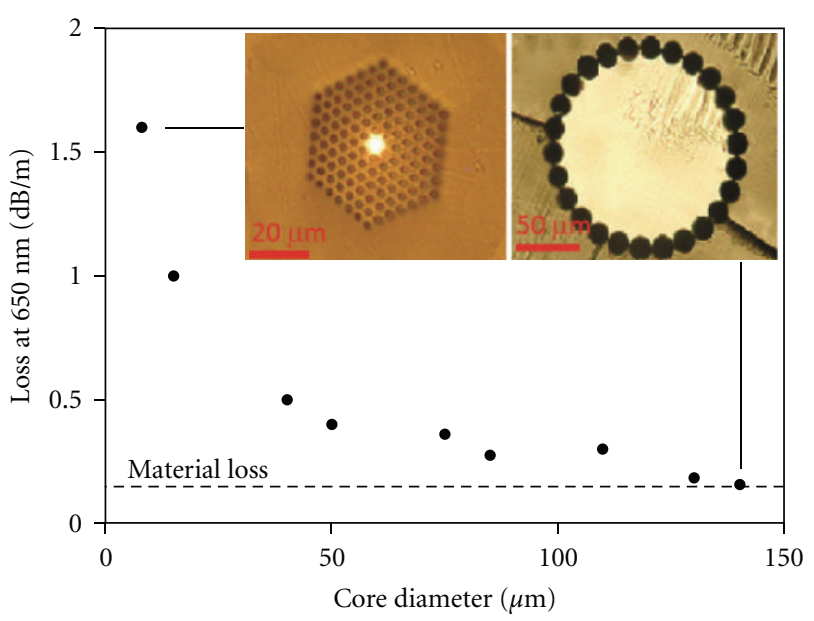

(a)

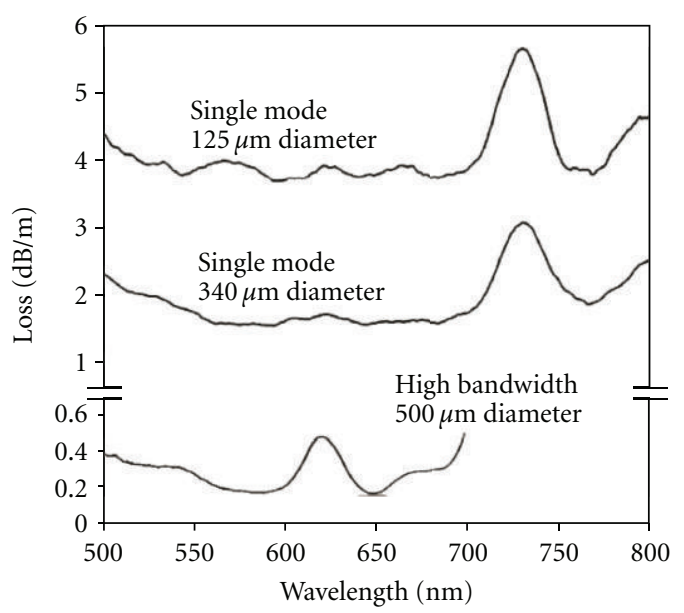

(b)

Figure 8: (a) Loss at $650 \mathrm{~nm}$ as a function of core diameter. Specific examples are the single-mode fibre of Figure 3(a) and the highbandwidth fibre of Figure 5(a). (b) Loss comparison of single-mode fibres for two outer diameters and the high-bandwidth fibre; note the break in the vertical axis. Adapted from [11].

waveguide itself and the surrounding air, for example, using plastic (HDPE) ribbons to obtain losses of $1 \mathrm{~cm}^{-1}$ [20]. Most of this work to date has been limited to demonstrating appropriately scaled waveguides that are known to work at other frequency ranges, without specifically addressing the requirements of working with terahertz frequency radiation.

The role of polymers here begins with identifying that polymers will remain flexible at relatively large diameters (on the $\mathrm{mm}$ scale), and the polymers with higher transparency have indices in the range commonly used in optics, meaning known waveguide designs could be easily adapted, as a start. This has led to investigations into solid-core, porous-core, and hollow-core terahertz waveguides based on microstructured polymer fibres.

5.1. Solid-Core Waveguides. HDPE and PTFE with losses as discussed in Section 2 and Table 1 were amongst the

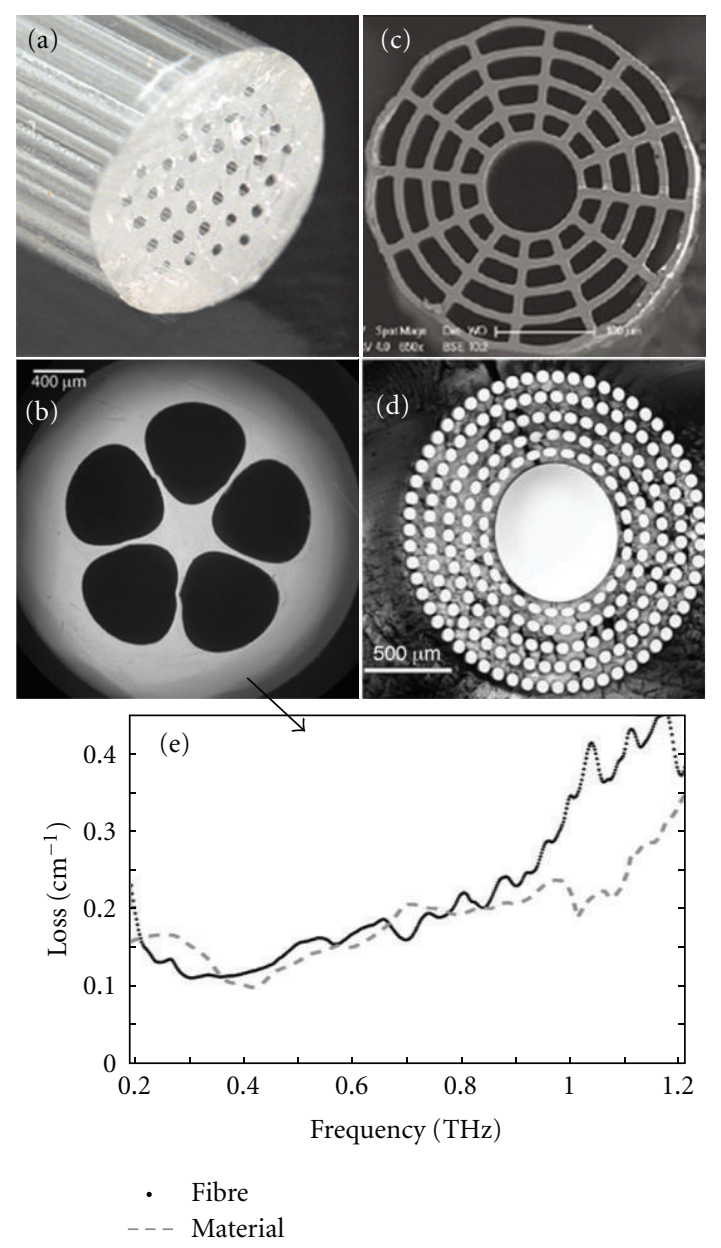

FIGURE 9: Solid-core microstructured polymer terahertz waveguides made of (a) Topas and (b) Zeonex. (c) A porous waveguide made of Topas. (d) A hollow-core waveguide made of PMMA. (e) Loss spectrum of the Zeonex waveguide shown in (b). Adapted from (a) [48], (b) and (e) [47], (c) [144], and (d) [145].

first polymers to be used in the context of microstructured polymer terahertz waveguides. Solid-core microstructured waveguides based on these polymers and the common hexagonal hole array were reported with losses of order $0.1 \mathrm{~cm}^{-1}$ and propagation lengths of $10 \mathrm{~cm}$ for the PTFE case [45], and losses of $0.5 \mathrm{~cm}^{-1}$ and propagation over $2 \mathrm{~cm}$ for the HDPE case [46]. More recently, Zeonex and Topas polymers which have lower loss were used. The Topas waveguide used the common hexagonal hole array as shown in Figure 9(a) and demonstrated propagation lengths of $9 \mathrm{~cm}$ [48]. The Zeonex waveguide used a suspended core design with five holes surrounding the core as shown in Figure 9(b) and demonstrated propagation lengths of $7 \mathrm{~cm}$ [47]. The Zeonex waveguide loss spectrum is shown in Figure 9(e), showing losses of order $0.1 \mathrm{~cm}^{-1}$, essentially matching the material loss. Indeed, the material loss ultimately determines the loss of such solid core waveguides and limits their use to short lengths. 


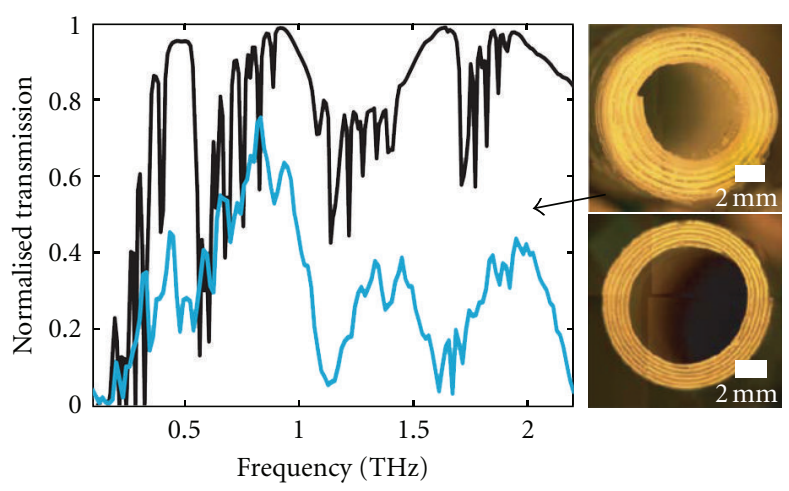

(a)

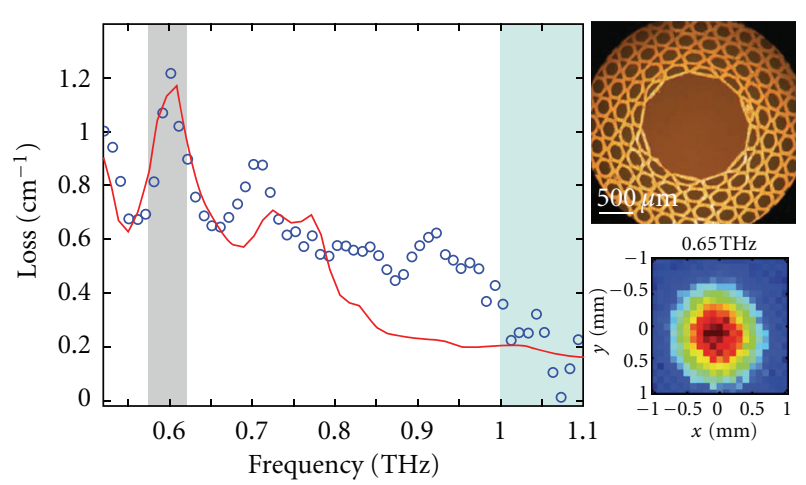

(b)

FIgure 10: (a) Polymer Bragg fibres using PTFE and $\mathrm{TiO}_{2}$-loaded HDPE. Graph shows normalised transmission theoretical values (black curve) and experimental values (blue curve) for the upper fibre of the inset. (b) Hollow-core kagome structure inhibited coupling waveguide made of PMMA. Graph shows theoretical loss values (red curve) and experimentally measured loss (blue circles). Inset shows fibre crosssection and mode profile, showing that these waveguides are single moded. Adapted from (a) [146] and (b) [150].

5.2. Porous Waveguides. The first approach to managing the material loss resulted in the use of so-called porous fibres, which consisted of a structured (porous) core with the surrounding air as the cladding [139-144]; an example is shown in Figure 9(c). The benefit arises from reducing the amount of solid material in the core, owing to the presence of the holes, and hence reducing the material absorption (and also affecting the average refractive index of the core and group velocity of the guided modes). Such an approach can potentially lead to a reduction in material loss by an order of magnitude, with predicted losses of order $0.01 \mathrm{~cm}^{-1}$ for cycloolefin-based waveguides at low frequencies [144].

The limitation here is that the waveguide consists of a bare core, and an exposed core is sensitive to external perturbations. However, this would be an advantage in some sensing applications, as discussed previously in the context of exposed core $\mathrm{mPOF}$ in the visible.

5.3. Hollow-Core Waveguides. The second approach to managing the material loss is to use a hollow core fibre and thus remove the material from the core altogether. This was discussed previously in Section 4.4 in the context of visible and infrared transmission. Unlike at higher frequencies, scattering losses are negligible for terahertz frequencies and material losses are sufficiently high that hollow-core waveguides offer a real advantage. The first such HC-mPOF for terahertz was made of PMMA with a Bragg fibre-like structure consisting of concentric rings of holes around the core [145] as shown in Figure 9(d), fabricated by drilling. The reported loss was $1-2 \mathrm{~dB} / \mathrm{cm}$ (approximately $0.25-0.5 \mathrm{~cm}^{-1}$ ) at around $1-1.3 \mathrm{THz}$, a factor of 30-60 times below the PMMA material loss at those frequencies [145]. The design of this waveguide was not optimised, and the total diameter was approximately $6 \mathrm{~mm}$. Other Bragg fibres were subsequently reported using $\mathrm{TiO}_{2}$-loaded HDPE for the high-index layers, and PTFE for the low-index layers, and the rolling fabrication technique of Figure 2(e) [146, 147]. An example of such fibres is shown in Figure 10(a). These had a total diameter of around $12 \mathrm{~mm}$, and estimated losses were of order $0.1 \mathrm{~cm}^{-1}$ within the transmission windows [147].

There are two further options for hollow-core microstructured waveguides beyond the Bragg fibres $[145,147]$ discussed previously: to use photonic bandgap guidance or the inhibited coupling mechanism. As discussed in Section 4.4, hollow-core bandgap waveguides will have a narrow spectral width of approximately $20 \%$ of the centre frequency (30\% of an octave) [148], but can achieve a lower loss of $<20 \mathrm{~dB} / \mathrm{km}$ in the infrared. Inhibited coupling based guidance in hollowcores has been demonstrated over a wider spectrum of $70 \%$ of the centre frequency (approximately 1 octave) with higher losses of $180 \mathrm{~dB} / \mathrm{km}$ [134]. The limits of this mechanism explored in a solid-core arrangement are shown in Figure 7 and predict transmission windows exceeding an octave [74]. The wider transmission bandwidth makes inhibited coupling waveguides an appealing option, and with their hollow core, they appear promising for two of the three criteria noted earlier. The "higher" loss is already orders of magnitude lower than any terahertz waveguide demonstrations.

The third criterion is the diameter of the waveguide, and inhibited coupling waveguides offer more flexibility to reduce the overall diameter for two important reasons. Firstly, inhibited coupling waveguides demonstrated thus far have consisted of a lattice of thin struts with a large pitch compared to the guided wavelength (and also to the lattice pitch of bandgap fibres operating at the same wavelength) [67$69,128-134]$. However, the critical parameter of the lattice that contributes to the inhibited coupling mechanism is the thickness of the struts and not the pitch. It is resonances across this thickness, rather than along the length of the struts, that determine the transmission windows of the fibre to a first approximation $[68,130,133]$. This means that the thickness of the waveguide can be reduced by reducing the pitch, whilst keeping the strut thickness constant. However, this may come at the cost of reducing the core size and 
increasing the loss as a result, and a study of this trade-off was reported in [149].

Secondly, it is not necessary to have a very thick cladding (i.e., many rings of holes surrounding the core) as the dominant loss mechanism in inhibited coupling fibres is coupling to cladding modes, and not tunnelling through the cladding as in bandgap fibres. Tunnelling can be reduced by extending the cladding outwards from the core, however, as this is not relevant to inhibited coupling fibres, the overall thickness of the cladding can be minimised to just a few rings of holes $[67,149]$.

An experimental demonstration of such an inhibited coupling waveguide using PMMA was also reported [150]. This was of a kagome lattice waveguide with a relatively short lattice pitch and thick struts, a core diameter of $2.2 \mathrm{~mm}$ and an overall diameter of $6.8 \mathrm{~mm}$. A transmission loss below $0.6 \mathrm{~cm}^{-1}$ was measured between 0.65 and $1 \mathrm{THz}$, which was approximately 20 times below the material loss of the PMMA. The near field of the output was also characterised to show single-mode operation.

Another approach utilising the inhibited coupling mechanism is to move away from a connected lattice, as in the original kagome fibre demonstrations [128], and towards a lattice of touching but disconnected circular tubes (such a design would be similar to the isolated PC tubes in a PMMA background shown in Figure 7 [74]). These fibres are called tube lattice fibres (TLFs) and have been demonstrated using silica for guidance in the infrared [151, 152]. The important characteristic here is the potentially wide transmission windows; transmission over two octaves of frequency was reported across several transmission windows in the near and mid-infrared [151]. A thorough theoretical investigation of these fibres for terahertz frequencies has shown them to be potentially low loss with wide transmission windows, one octave or greater, whilst larger bandwidths may again be guided across multiple transmission windows [153-155]. This has been accompanied by a study of the guidance mechanisms specific to TLF to increase understanding of their operation, and hence aid with future designs [156, 157]. The circular individual tubes also contribute to lower the loss as compared to a usual kagome lattice, which consists of straight segments in the cladding $[134,151,158]$. Predicted dimensions for such waveguide designs are of order $1 \mathrm{~cm}$, thus they also remain promising in terms of flexibility.

5.4. Outlook. Work on microstructured polymer terahertz waveguides continues, and progress has been made towards overcoming the material losses, broadening transmission windows, and reducing the diameter of the waveguides to achieve flexibility. The combination of Zeonex or Topas with hollow-core TLF waveguides seems like a promising avenue to achieve low-loss flexible waveguides. The limitations in this work are the material loss, large frequency range, and large wavelengths; the field is still new, and whilst work has aimed at overcoming these latter three limitations, the limitations of the approaches taken remain unclear at this early stage. Research into terahertz waveguides in general is still ongoing, and any work using the options discussed here must ultimately be compared to other approaches not confined to microstructured polymer waveguides, such as hollow metalcoated tube waveguides, for example. Currently, there is no single approach that clearly outperforms others.

\section{Drawn Metamaterials}

Metamaterials are man-made composites that obtain their properties from their structure. This structure can be composed of individual meta-atoms, metal-dielectric structures that are designed to have specific properties. In particular, a metamaterial will have electromagnetic properties (permittivity and permeability) that arise from the properties of these meta-atoms, such as their resonances, in the same way as regular materials derive their properties from the resonances of real atoms $[22,24,25]$. This allows metamaterials to have engineered electric and magnetic responses, and most interestingly, this allows responses not found in nature to be achieved. Naturally occurring materials are generally summarised as having large negative relative permittivity for metals, small positive relative permittivity for dielectrics, and a relative permeability of 1 in the frequency range concerning this paper. The properties of metamaterials can deviate significantly from these values.

This paper does not in any way seek to cover the vast field of metamaterials in its entirety. One aspect of metamaterials is that the meta-atoms and the structures within them are subwavelength. This requires fabrication on a small scale $(100 \mathrm{~nm}$ and below for the visible, to $100 \mu \mathrm{m}$ scales for $\mathrm{THz}$ ), which is usually incompatible with fabrication in large volumes. The area that will be addressed in this paper is the use of fibre drawing techniques based on microstructured polymer fibres, to fabricate metamaterials. Fibre drawing (as in $\mathrm{MPOF}$ ) produces micron-scaled features in large quantities and offers a potentially scalable method for the fabrication of metamaterials when the microstructure is filled with metal. There are two basic meta-atoms which are easily understood: wire arrays which control the permittivity [159], and resonators which are similar to LC circuits with a magnetic resonance, and control permeability [22]. Both wire arrays and resonators are compatible with fibre drawing and the resulting longitudinally invariant geometry.

6.1. Wire Arrays: Electric Metamaterials. The electromagnetic properties of metals can be described by a Drude model and characterised by a plasma frequency in the UV. Below this plasma frequency, metallic behaviour is observed, characterised by negative permittivity, $\varepsilon<0$, and strong reflection. Above it, dielectric behaviour is observed with $\varepsilon>0$ and transmission. The plasma frequency corresponds to $\varepsilon=0$ and depends on the electrons' effective mass in the metal and the electron density. If a metal is broken up into subwavelength wires, self and mutual inductance of the wires results in a change to the electrons' effective mass, and the average electron density (averaged on the scale of a wavelength) is reduced in comparison to the bulk metal. These effects (predominantly the former) result in the plasma frequency shifting to lower frequencies. This approach allows 
the permittivity at a particular frequency to be adjusted by adjusting the size and spacing between the wires in such a subwavelength wire array $[159,160]$. Furthermore, such a wire array will have a highly anisotropic permittivity tensor, with only $\varepsilon_{z z}$ being described by such a modified Drude model (electric field parallel to the wires). For electric field oriented transverse to the wires, the permittivity will be very close to that of the dielectric medium in which the wires are embedded.

Wire arrays are obviously compatible with fibre drawing and are intrinsically longitudinally invariant. Fibre drawing to fabricate wires was investigated since the 1920s in the Taylor wire process [78], and more recently optical fibres with wires were investigated in the study of surface plasmons $[161,162]$. In terms of wire array metamaterials, wire arrays have been made using PMMA as the base material and the general methods described in Section 3 [75]. Indium metal was used in this work as it melts at $156.6^{\circ} \mathrm{C}$ and is thus liquid at the fibre drawing temperatures of approximately $200^{\circ} \mathrm{C}$. Indium wire was inserted into PMMA tubes, which were drawn to a smaller diameter. The resulting wires were stacked together inside a larger tube to form the array and drawn a second time to achieve the desired dimensions. The final fibres were assembled into an array and characterised. The reported case in [75] had wires of approximately $8 \mu \mathrm{m}$ diameter at $100 \mu \mathrm{m}$ spacing, which resulted in a plasma frequency in the vicinity of $0.2-0.3 \mathrm{THz}$, depending on the exact dimensions of the fibre. An example of this wire array fibre and its transmittance are shown in Figure 11. The plasma frequency is inferred from the transition from dielectric behaviour observed at higher frequencies indicated by high transmittance, to metallic behaviour at low frequencies, indicated by poor transmittance. Excellent agreement with simulations was noted $[75,159,160]$.

6.2. Resonators: Magnetic Metamaterials. To achieve a magnetic response, an open loop of wire in the shape of a "C" (a split ring resonator, SRR) or two such concentric loops rotated $180^{\circ}$ relative to each other (a double split ring resonator, DSSR) can be used, as seen in Figure 12. The gap in the open ring of the SRR or between the two rings in a DSRR creates a capacitance, and the curved shape creates an inductance. As a result, these structures have an LC resonance and will result in a magnetic response at high frequencies and from nonmagnetic materials $[22,163]$. This resonance will be driven by a magnetic field perpendicular to the plane of the resonator (and also electric fields parallel to the gap in a SRR). Such resonators will continue to work in the longitudinally invariant case that would result from fibre drawing. The resulting metamaterial will also be anisotropic, having a permeability $\mu$ described by a resonance in the $\mu_{z z}$ component (magnetic field parallel to the fibre axis), whilst $\mu$ will correspond to the free space value for transverse magnetic field components. Interestingly, apart from achieving a magnetic response at high frequencies, if the resonance is strong enough, it will result in a negative permeability and a magnetic plasma frequency, where $\mu=0$.

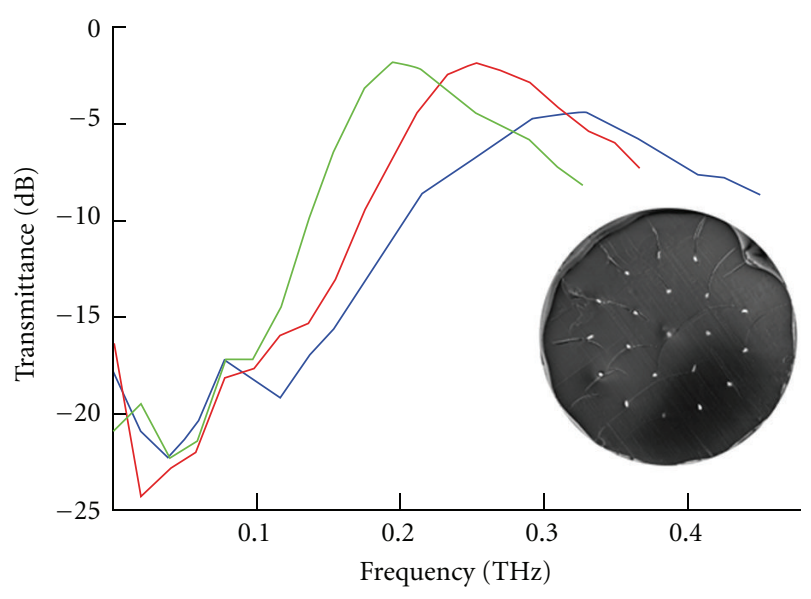

FIGURE 11: Wire array metamaterial composed of indium wires in a PMMA fibre, resulting in a tailored permittivity, described by a plasma frequency at approximately $0.2-0.3 \mathrm{THz}$ for radiation with the electric field parallel to the wires. The reduction in transmission at higher frequencies arises from dielectric resonances. The three coloured curves represent fibres of slightly different sizes, with green being the largest and blue the smallest. Adapted from [75].

Such resonators were also fabricated using drawing methods and combinations of PMMA, PC, and Zeonex [76, 77]. The preforms were assembled by rolling indium sheet around a PMMA tube, with a PMMA rod filling a gap in the sheet to create the split in the ring (twice for DSRRs). This assembly was then inserted inside a PC tube to form the preform and drawn to fibre in several stages. A PMMA tube was used in the inner sections of the resonator as the inner sections are shielded by the metal and remain slightly colder compared to the outer part of the preform. Hence, using a PMMA tube (hollow, and with a lower $T_{g}$ ) inside and PC (higher $T_{g}$ ) outside helped to ensure that the viscosity of the polymer was uniform across the preform [76].

In the SRR case, the resonators were further stacked inside a rectangular Zeonex slab [76]. Zeonex was used for its transparency in the THz as discussed in Sections 2 and 5. This created "sheets" of resonator arrays that could be assembled, a first step towards forming bulk 3D metamaterials from this method, as shown in Figure 12(b). The final resonators were $100-350 \mu \mathrm{m}$ in diameter and had magnetic resonances between 0.1 and $0.4 \mathrm{THz}$. The resonances were characterised by a reduction in the transmittance; an example is shown in Figure 12(d).

In the DSRR case, sleeving was required to increase the outer diameter and help preserve the structure of the two rings. The sleeve was later removed by etching. PMMA and Zeonex sleeves were reported, but the Zeonex here was used not for its transparency but because it could be removed with cyclohexane, a solvent that does not affect the PMMA and PC in the resonators themselves [77]. An example of an etched fibre is shown in Figure 12(c). Such fibres once etched were also assembled into arrays and characterised in terms of transmittance. The final resonator sizes were approximately $100 \mu \mathrm{m}$ in diameter, and resonances 


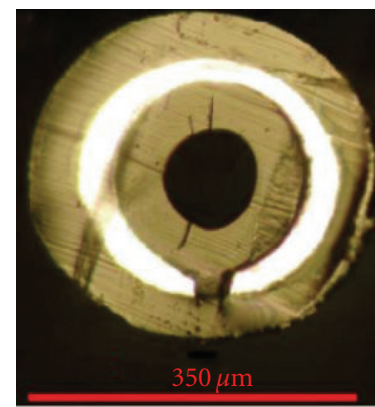

(a)

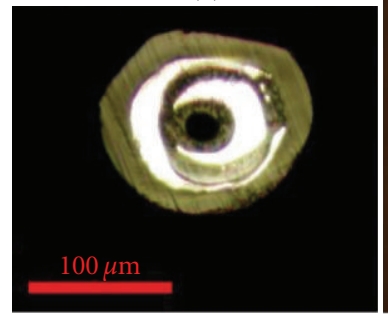

(c)

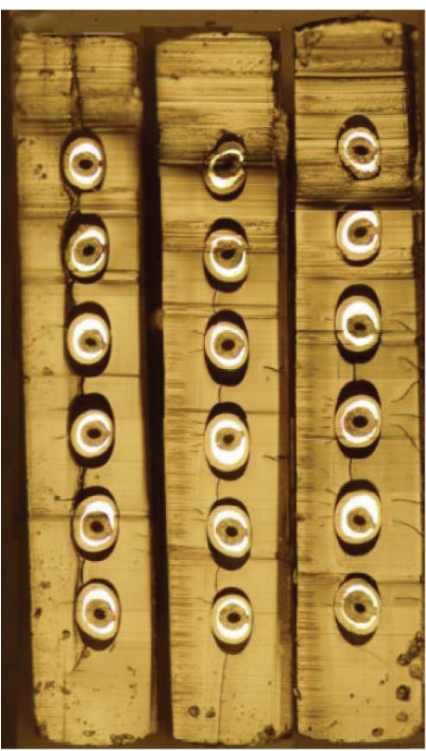

(b)

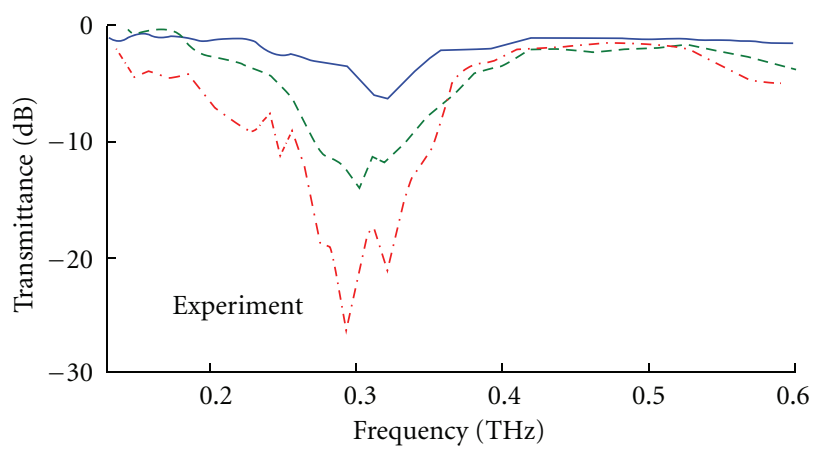

$$
\begin{aligned}
& -1 \text { Layer } \\
& ---\quad 2 \text { Layer } \\
& -\cdot-\quad 3 \text { Layer }
\end{aligned}
$$

(d)

Figure 12: Magnetic resonator fibres containing indium metal. (a) A split ring resonator fibre with PMMA in the inner part of the indium resonator and PC on the outer. (b) A layered array of such fibres consolidated in Zeonex slabs. (c) A double split ring resonator fibre. (d) The transmittance of arrays as in (b) consisting of 1, 2, or 3 layers, characterised by the magnetic field of the radiation parallel to the fibre axis. The magnetic resonance is indicated by the drop in transmittance at $0.3 \mathrm{THz}$. Adapted from (a), (b), and (d) [76] and (c) [77].

at $0.25 \mathrm{THz}$ were observed. These resonators were smaller relative to the resonant wavelength compared to SRR, meaning a homogenous material would be more easily achieved. This work also showed that fibre drawing could be extended to more complex meta-atoms.

6.3. Future Directions and Limitations. The work on drawn metamaterials is still in its early days. Basic control over the electric and magnetic response has been demonstrated with the wire array and magnetic resonator fibres, within the constraints of the longitudinally invariant fibre geometry. Potential extensions of this work include more complex structures in fibres and combinations of fibres to produce metamaterials composed of multiple meta-atoms. For example, woven metamaterial structures could be realised with magnetic resonator fibres woven perpendicular to wire array fibres. If a negative permeability and permittivity are combined in such a way, a negative refractive index [21] drawn metamaterial fabric could be achieved. The smaller resonator to wavelength ratio observed for DSRR would be advantageous in such cases that require multiple components to be assembled. This work also has the potential to be extended to the various metamaterial devices that are currently being investigated, such as metamaterial lenses and cloaking [26-28, 30].

In addition to metamaterials themselves, recent theoretical work into metamaterial-based waveguides has reported on many designs that would be compatible with the fibre drawing process [164-166]. These offer the potential for relatively small and even subwavelength confinement of radiation. This is particularly relevant to terahertz waveguides discussed in Section 5, where the size of the wavelength is an issue, and provide an alternative approach to investigating thin waveguides.

The limitations of drawn metamaterials have not fully been explored. Investigations thus far have been on the scale of 10 to $100 \mu \mathrm{m}$ and at terahertz frequencies. Whether the extension to smaller sizes and higher frequencies into the infrared and visible is possible remains unclear. Work in the visible would require 10 to $100 \mathrm{~nm}$ scales, which have been fabricated in other material fibre systems [167]. Furthermore, losses due to metals and the potential for introducing gain are a concern for metamaterials research in general. At higher frequencies, gold and silver are known to have preferable optical properties, but their high melting points $\left(\sim 1000^{\circ} \mathrm{C}\right)$ make them incompatible with any polymer.

The use of polymer has been a key in this work as it built on the existing fabrication techniques developed for mPOF described in Section 3 and allowed these fabrication methods and metamaterials to be investigated on a short time scale using an inexpensive fabrication and material system. In the case of terahertz metamaterials, polymers offer the additional advantage in the transparency of Zeonex and Topas. Ultimately, metamaterials obtain their properties from their structure; however, one important way in which the constituent materials contribute is through their absorption. At higher frequencies, other material systems with lower loss, particularly metals, may be preferred.

\section{Conclusion}

The work on microstructured polymer fibres, as outlined previously, has progressed through the three distinct areas of optical fibres, terahertz waveguides, and drawn metamaterials. The optical fibre work, mPOF, is the most developed, having begun the earliest, and has reached the point where specific applications are being pursued. These applications are in sensing, particularly through the use of gratings, 
and short-distance data transmission. In these cases, the use of microstructure and polymer offers distinct quantified advantages, such as larger elastic limits, versatile fabrication techniques, higher data rates, and significantly lower loss in the simple case of a polymer single-mode fibre for the visible, which in turn enables much of the work on gratings. As a technology, its operation and limitations are largely understood, and other than any possible technological developments, no significant change in this field is expected. Such changes are of course possible, but would need to be triggered by a new research effort and a qualitatively different approach to what has been demonstrated thus far, a good example being the potential widespread use of (currently unavailable) fluorinated materials. These could significantly reduce the loss of mPOF and allow their use at telecommunications wavelengths, as discussed in Section 4.5.

The work on terahertz waveguides and drawn metamaterials is still in its infancy in comparison. Waveguide designs are in the process of being developed and refined for use at terahertz frequencies, and polymers are an excellent material in which to fabricate them. The terahertz field itself is still emerging, and components taken for granted in the visible and infrared, low-loss flexible waveguides in this context, would find immediate uses in research and eventually possibly in real applications.

The drawn metamaterials work has also barely reached beyond the proof of concept stage, with only the basic electric and magnetic metamaterial fibres having been reported. Extensions of this work to more complex fibre geometries, higher frequencies, and to metamaterial devices containing these fibres will surely follow. The potential of the fibre drawing technique is its inherent scalability to large volumes, and this may prove advantageous when metamaterials such as these begin finding applications.

\section{References}

[1] M. A. Van Eijkelenborg, M. C. J. Large, A. Argyros et al., "Microstructured polymer optical fibre," Optics Express, vol. 9, no. 7, pp. 319-327, 2001.

[2] M. A. Van Eijkelenborg, A. Argyros, G. Barton et al., "Recent progress in microstructured polymer optical fibre fabrication and characterisation," Optical Fiber Technology, vol. 9, no. 4, pp. 199-209, 2003.

[3] M. C. J. Large, A. Argyros, F. Cox et al., "Microstructured polymer optical fibres: new opportunities and challenges," Molecular Crystals and Liquid Crystals, vol. 446, pp. 219-231, 2006.

[4] M. C. J. Large, G. W. Barton, L. Poladian, and M. A. van Eijkelenborg, Microstructured Polymer Optical Fibres, Springer, Berlin, Germany, 2007.

[5] A. Argyros, "Microstructured polymer optical fibres," Journal of Lightwave Technology, vol. 27, no. 11, pp. 1571-1579, 2009.

[6] J. C. Knight, T. A. Birks, P. S. J. Russell, and D. M. Atkin, "Allsilica single-mode optical fiber with photonic crystal cladding," Optics Letters, vol. 21, no. 19, pp. 1547-1549, 1996.

[7] P. St. J. Russell, “Photonic crystal fibers," Science, vol. 299, no. 5605, pp. 358-362, 2003.
[8] J. C. Knight, "Photonic crystal fibres," Nature, vol. 424, no. 6950, pp. 847-851, 2003.

[9] P. S. J. Russell, "Photonic-crystal fibers," Journal of Lightwave Technology, vol. 24, no. 12, pp. 4729-4749, 2006.

[10] O. Ziemann, J. Krauser, P. E. Zamzow, and W. Daum, POF Handbook, Springer, Belrin, Germany, 2008.

[11] A. Argyros, R. Lwin, S. G. Leon-Saval, J. Poulin, L. Poladian, and M. C. J. Large, "Low loss and temperature stable microstructured polymer optical fibres," Journal of Lightwave Technology, vol. 30, no. 1, pp. 192-197, 2012.

[12] R. Provo, S. G. Murdoch, J. D. Harvey, R. Lwin, S. G. LeonSaval, and A. Argyros, "Error free 9. $5 \mathrm{~Gb} / \mathrm{s}$ transmission over $50 \mathrm{~m}$ of multimode microstructured polymer optical fibres," in Proceedings of the Quantum Electronics Conference \& Lasers and Electro-Optics Conference, pp. 784-786, Sydney, Australia.

[13] Y. Shi, C. Okonkwo, A. Argyros et al., "7. 3 Gbit/s transmission over microstructured polymer optical fiber for in-home networks," IEEE Photonics Technology Letters, vol. 24, no. 14, pp. 1257-1259, 2012.

[14] B. Ferguson and X. C. Zhang, "Materials for terahertz science and technology," Nature Materials, vol. 1, no. 1, pp. 26-33, 2002.

[15] M. Tonouchi, "Cutting-edge terahertz technology," Nature Photonics, vol. 1, no. 2, pp. 97-105, 2007.

[16] B. S. Williams, "Terahertz quantum-cascade lasers," Nature Photonics, vol. 1, no. 9, pp. 517-525, 2007.

[17] W. L. Chan, J. Deibel, and D. M. Mittleman, "Imaging with terahertz radiation," Reports on Progress in Physics, vol. 70, no. 8, article no. R02, pp. 1325-1379, 2007.

[18] ZOmega Terahertz Corporation, "The Terahertz Wave Ebook," 2012, http://dl.z-thz.com/eBook/zomega_ebook_pdf_1206_sr .pdf.

[19] Y. S. Jin, G. J. Kim, and S. G. Jeon, "Terahertz dielectric properties of polymers," Journal of the Korean Physical Society, vol. 49, no. 2, pp. 513-517, 2006.

[20] R. Mendis and D. Grischkowsky, "Plastic ribbon THz waveguides," Journal of Applied Physics, vol. 88, no. 7, pp. 4449-4451, 2000.

[21] V. G. Veselago, "Electrodynamics of substances with simultaneously negative values of sigma and mu," Soviet Physics UspeckhiUSSR, vol. 10, no. 4, p. 509, 1968.

[22] J. B. Pendry, A. J. Holden, D. J. Robbins, and W. J. Stewart, "Magnetism from conductors and enhanced nonlinear phenomena," IEEE Transactions on Microwave Theory and Techniques, vol. 47, no. 11, pp. 2075-2084, 1999.

[23] R. A. Shelby, D. R. Smith, and S. Schultz, "Experimental verification of a negative index of refraction," Science, vol. 292, no. 5514, pp. 77-79, 2001.

[24] W. Cai and V. Shalaev, Optical Metamaterials: fundamentals and Applications, Springer, 2009.

[25] R. C. McPhedran, I. V. Shadrivov, B. T. Kuhlmey, and Y. S. Kivshar, "Metamaterials and metaoptics," NPG Asia Materials, vol. 3, pp. 100-108, 2011.

[26] J. B. Pendry, "Negative refraction makes a perfect lens," Physical Review Letters, vol. 85, no. 18, pp. 3966-3969, 2000.

[27] Z. Jacob, L. V. Alekseyev, and E. Narimanov, "Optical hyperlens: far-field imaging beyond the diffraction limit," Optics Express, vol. 14, no. 18, pp. 8247-8256, 2006.

[28] Z. Liu, H. Lee, Y. Xiong, C. Sun, and X. Zhang, "Far-field optical hyperlens magnifying sub-diffraction-limited objects," Science, vol. 315 , no. 5819, p. 1686, 2007. 
[29] J. B. Pendry, D. Schurig, and D. R. Smith, "Controlling electromagnetic fields," Science, vol. 312, no. 5781, pp. 1780-1782, 2006.

[30] D. Schurig, J. J. Mock, B. J. Justice et al., "Metamaterial electromagnetic cloak at microwave frequencies," Science, vol. 314, no. 5801, pp. 977-980, 2006.

[31] A. Boltasseva and V. M. Shalaev, "Fabrication of optical negative-index metamaterials: recent advances and outlook," Metamaterials, vol. 2, no. 1, pp. 1-17, 2008.

[32] M. Walther, A. Ortner, H. Meier, U. Löffelmann, P. J. Smith, and J. G. Korvink, "Terahertz metamaterials fabricated by inkjet printing," Applied Physics Letters, vol. 95, no. 25, Article ID 251107, 2009.

[33] http://www.pofeska.com/pofeskae/.

[34] http://www.optimedia.co.kr/eng_optimedia_main_a_01.htm.

[35] http://www.luceat.it/inglese/cavi.htm.

[36] T. A. Birks, J. C. Knight, and P. S. J. Russell, "Endlessly singlemode photonic crystal fiber," Optics Letters, vol. 22, no. 13, pp. 961-963, 1997.

[37] Y. Gao, N. Guo, B. Gauvreau et al., "Consecutive solvent evaporation and co-rolling techniques for polymer multilayer hollow fiber preform fabrication," Journal of Materials Research, vol. 21, no. 9, pp. 2246-2254, 2006.

[38] M. A. Van Eijkelenborg, A. Argyros, and S. G. Leon-Saval, "Polycarbonate hollow-core microstructured optical fiber," Optics Letters, vol. 33, no. 21, pp. 2446-2448, 2008.

[39] S. Irie and M. Nishiguchi, "Development of the resistant plastic optical fiber," in Proceedings of the International Conference on Plastic Optical Fibers, p. 88, 1994.

[40] J. Zubia and J. Arrue, "Plastic optical fibers: an introduction to their technological processes and applications," Optical Fiber Technology, vol. 7, no. 2, pp. 101-140, 2001.

[41] S. G. Leon-Saval, R. Lwin, and A. Argyros, "Multicore composite single-mode polymer fiber," Optics Express, vol. 20, no. 1, pp. 141-148, 2012.

[42] http://www.zeonex.com/.

[43] G. Emiliyanov, J. B. Jensen, O. Bang et al., "Localized biosensing with Topas microstructured polymer optical fiber," Optics Letters, vol. 32, no. 5, pp. 460-462, 2007.

[44] http://www.topas.com/products-topas_coc.

[45] M. Goto, A. Quema, H. Takahashi, S. Ono, and N. Sarukura, "Teflon photonic crystal fiber as terahertz waveguide," Japanese Journal of Applied Physics, Part 2, vol. 43, no. 2 B, pp. L317-L319, 2004.

[46] H. Han, H. Park, M. Cho, and J. Kim, "Terahertz pulse propagation in a plastic photonic crystal fiber," Applied Physics Letters, vol. 80, no. 15, pp. 2634-2636, 2002.

[47] J. Anthony, R. Leonhardt, A. Argyros, and M. C. J. Large, "Characterization of a microstructured Zeonex terahertz fiber," Journal of the Optical Society of America B, vol. 28, no. 5, pp. 1013-1018, 2011.

[48] K. Nielsen, H. K. Rasmussen, A. J. L. Adam, P. C. M. Planken, O. Bang, and P. U. Jepsen, "Bendable, low-loss Topas fibers for the terahertz frequency range," Optics Express, vol. 17, no. 10, pp. 8592-8601, 2009.

[49] Y. Koike and M. Asai, “The future of plastic optical fiber," $N P G$ Asia Materials, vol. 1, pp. 22-28, 2009.

[50] S. Kondo, T. Ishigure, and Y. Koike, "Fabrication of polymer photonic crystal fiber," in Proceedings of the Micro-Optics Conference (MOC '11), vol. 10, p. B-7, 2004.

[51] http://www.agcce.com/CYTOP/TechInfo.asp.
[52] G. De Los Reyes, A. Quema, C. Ponseca Jr. et al., "Lowloss single-mode terahertz waveguiding using Cytop," Applied Physics Letters, vol. 89, no. 21, Article ID 211119, 2006.

[53] A. Kondo, T. Ishigure, and Y. Koike, "Low-loss and highbandwidth deuterated PMMA based graded-index polymer optical fiber," in Proceedings of the International Conference on Plastic Optical Fibers, pp. 285-292, 2004.

[54] E. H. Min, K. H. Wong, E. Setijadi, F. Ladouceur, M. Straton, and A. Argyros, "Menthol-based chiral copolymers for polymer optical fibers (POF)," Polymer Chemistry, vol. 2, no. 9, pp. 20452051, 2011.

[55] L. Poladian, M. Straton, A. Docherty, and A. Argyros, "Pure chiral optical fibres," Optics Express, vol. 19, no. 2, pp. 968-980, 2011.

[56] A. Dupuis, N. Guo, Y. Gao et al., "Prospective for biodegradable microstructured optical fibers," Optics Letters, vol. 32, no. 2, pp. 109-111, 2007.

[57] M. C. J. Large, S. Ponrathnam, A. Argyros, N. S. Pujari, and F. Cox, "Solution doping of microstructured polymer optical fibres," Optics Express, vol. 12, no. 9, pp. 1966-1971, 2004.

[58] K. Li, X. Yang, L. Wang, and W. Zhao, "Dye-doped microstructured polymer optical fibre laser with high numerical aperture air-clad," in Proceedings of the Conference on Lasers and ElectroOptics, CML4, 2007.

[59] Y. Zhang, K. Li, L. Wang et al., "Casting preforms for microstructured polymer optical fibre fabrication," Optics Express, vol. 14, no. 12, pp. 5541-5547, 2006.

[60] H. C. Y. Yu, A. Argyros, G. Barton et al., "Quantum dot and silica nanoparticle doped polymer optical fibers," Optics Express, vol. 15, no. 16, pp. 9989-9994, 2007.

[61] H. C. Y. Yu, M. A. Van Eijkelenborg, S. G. Leon-Saval, A. Argyros, and G. W. Barton, "Enhanced magneto-optical effect in cobalt nanoparticle-doped optical fiber," Applied Optics, vol. 47, no. 35, pp. 6497-6501, 2008.

[62] H. C. Y. Yu, A. Argyros, S. G. Leon-Saval, A. Fuerbach, A. Efimov, and G. W. Barton, "Emission properties of quantum dots in polymer optical fibres," Optics Express, vol. 17, no. 24, pp. 21344-21349, 2009.

[63] H. C. Y. Yu, S. G. Leon-Saval, A. Argyros, and G. W. Barton, "Temperature effects on emission of quantum dots embedded in polymethylmethacrylate," Applied Optics, vol. 49, no. 15, pp. 2749-2752, 2010.

[64] G. Barton, M. A. Van Eijkelenborg, G. Henry, M. C. J. Large, and J. Zagari, "Fabrication of microstructured polymer optical fibres," Optical Fiber Technology, vol. 10, no. 4, pp. 325-335, 2004.

[65] A. Argyros, I. M. Bassett, M. A. Van Eijkelenborg et al., "Ring structures in microstructured polymer optical fibres," Optics Express, vol. 9, no. 13, pp. 813-820, 2001.

[66] H. Ebendorff-Heidepriem, T. M. Monro, M. A. van Eijkelenborg, and M. C. J. Large, "Extruded high-NA microstructured polymer optical fibre," Optics Communications, vol. 273, no. 1, pp. 133-137, 2007.

[67] A. Argyros and J. Pla, "Hollow-core polymer fibres with a kagome lattice: potential for transmission in the infrared," Optics Express, vol. 15, no. 12, pp. 7713-7719, 2007.

[68] A. Argyros, S. G. Leon-Saval, J. Pla, and A. Docherty, "Antiresonant reflection and inhibited coupling in hollow-core square lattice optical fibres," Optics Express, vol. 16, no. 8, pp. 56425648, 2008.

[69] A. Argyros, S. G. Leon-Saval, and M. A. van Eijkelenborg, “Twin-hollow-core optical fibres," Optics Communications, vol. 282, no. 9, pp. 1785-1788, 2009. 
[70] B. Temelkuran, S. D. Hart, G. Benoit, J. D. Joannopoulos, and Y. Fink, "Wavelength-scalable hollow optical fibres with large photonic bandgaps for $\mathrm{CO}_{2}$ laser transmission," Nature, vol. 420, no. 6916, pp. 650-653, 2002.

[71] B. Gauvreau, N. Guo, K. Schicker et al., "Color-changing and color-tunable photonic bandgap fiber textiles," Optics Express, vol. 16, no. 20, pp. 15677-15693, 2008.

[72] A. F. Abouraddy, M. Bayindir, G. Benoit et al., "Towards multimaterial multifunctional fibres that see, hear, sense and communicate," Nature Materials, vol. 6, no. 5, pp. 336-347, 2007.

[73] J. J. Kaufman, G. Tao, S. Shabahang et al., "Structured spheres generated by an in-fibre fluid instability," Nature, vol. 487, pp. 463-467, 2012.

[74] T. Grujic, B. T. Kuhlmey, A. Argyros, S. Coen, and C. M. De Sterke, "Solid-core fiber with ultra-wide bandwidth transmission window due to inhibited coupling," Optics Express, vol. 18, no. 25, pp. 25556-25566, 2010.

[75] A. Tuniz, B. T. Kuhlmey, R. Lwin et al., "Drawn metamaterials with plasmonic response at terahertz frequencies," Applied Physics Letters, vol. 96, no. 19, Article ID 191101, 2010.

[76] A. Tuniz, R. Lwin, A. Argyros et al., "Stacked-and-drawn metamaterials with magnetic resonances in the terahertz range," Optics Express, vol. 19, no. 17, pp. 16480-16490, 2011.

[77] N. Singh, A. Tuniz, R. Lwin et al., "Fiber-draw double split ring resonators in the terahertz range," Optical Materials Express, vol. 2, no. 9, pp. 1254-1259, 2012.

[78] G. F. Taylor, "A method of drawing metallic filaments and a discussion of their properties and uses," Physical Review, vol. 23, no. 5, pp. 655-660, 1924.

[79] S. C. Xue, R. I. Tanner, G. W. Barton, R. Lwin, M. C. J. Large, and L. Poladian, "Fabrication of microstructured optical fibers - part I: problem formulation and numerical modeling of transient draw process," Journal of Lightwave Technology, vol. 23, no. 7, pp. 2245-2254, 2005.

[80] S. C. Xue, R. I. Tanner, G. W. Barton, R. Lwin, M. C. J. Large, and L. Poladian, "Fabrication of microstructured optical fiberspart II: numerical modeling of steady-state draw process," Journal of Lightwave Technology, vol. 23, no. 7, pp. 2255-2266, 2005.

[81] S. C. Xue, M. C. J. Large, G. W. Barton, R. I. Tanner, L. Poladian, and R. Lwin, "Role of material properties and drawing conditions in the fabrication of microstructured optical fibers," Journal of Lightwave Technology, vol. 24, no. 2, pp. 853-860, 2006.

[82] S. C. Xue, L. Poladian, G. W. Barton, and M. C. J. Large, "Radiative heat transfer in preforms for microstructured optical fibres," International Journal of Heat and Mass Transfer, vol. 50, no. 7-8, pp. 1569-1576, 2007.

[83] S. C. Xue, R. Lwin, G. W. Barton, L. Poladian, and M. C. J. Large, "Transient heating of PMMA preforms for microstructured optical fibers," Journal of Lightwave Technology, vol. 25, no. 5, pp. 1177-1183, 2007.

[84] J. K. Ranka, R. S. Windeler, and A. J. Stentz, "Visible continuum generation in air-silica microstructure optical fibers with anomalous dispersion at $800 \mathrm{~nm}$," Optics Letters, vol. 25, no. 1, pp. 25-27, 2000.

[85] F. Röser, J. Rothhard, B. Ortac et al., "131 W 220 fs fiber laser system," Optics Letters, vol. 30, no. 20, pp. 2754-2756, 2005.

[86] J. Limpert, O. Schmidt, J. Rothhardt et al., "Extended singlemode photonic crystal fiber lasers," Optics Express, vol. 14, no. 7, pp. 2715-2720, 2006.
[87] A. Tünnermann, T. Schreiber, F. Röser et al., "The renaissance and bright future of fibre lasers," Journal of Physics B, vol. 38, no. 9, pp. S681-S693, 2005.

[88] A. Argyros, M. A. Van Eijkelenborg, S. D. Jackson, and R. P. Mildren, "Microstructured polymer fiber laser," Optics Letters, vol. 29, no. 16, pp. 1882-1884, 2004.

[89] A. Argyros, M. A. van Eijkelenborg, S. D. Jackson, and R. P. Mildren, "Reply to comment on: a microstructured polymer fiber laser," Optics Letters, vol. 30, no. 14, pp. 1829-1830, 2005.

[90] H. Dobb, D. J. Webb, K. Kalli, A. Argyros, M. C. J. Large, and M. A. Van Eijkelenborg, "Continuous wave ultraviolet light-induced fiber Bragg gratings in few- And single-mode microstructured polymer optical fibers," Optics Letters, vol. 30, no. 24, pp. 3296-3298, 2005.

[91] M. P. Hiscocks, M. A. Van Eijkelenborg, A. Argyros, and M. C. J. Large, "Stable imprinting of long-period gratings in microstructured polymer optical fibre," Optics Express, vol. 14, no. 11, pp. 4644-4649, 2006.

[92] M. C. J. Large, J. Moran, and L. Ye, "The role of viscoelastic properties in strain testing using microstructured polymer optical fibres (mPOF)," Measurement Science and Technology, vol. 20, no. 3, Article ID 034014, 2009.

[93] M. C. J. Large, D. Blacket, and C. A. Bunge, "Microstructured polymer optical fibers compared to conventional POF: novel properties and applications," IEEE Sensors Journal, vol. 10, no. 7, pp. 1213-1217, 2010.

[94] M. Steffen, M. Schukar, J. Witt, K. Krebber, M. Large, and A. Argyros, "Investigation of mPOF LPGs for sensing applications," in Proceedings of the International Conference on Plastic Optical Fibres, paper 25, p. 26, 2009.

[95] G. Durana, J. Gomez, G. Aldabaldetreku, J. Zubia, A. Montero, and I. Saez de Ocariz, "Assessment of an LPG mPOF for strain sensing," IEEE Sensors Journal, vol. 12, no. 8, pp. 2668-2673, 2012.

[96] A. Argyros, S. G. Leon-Saval, R. Lwin et al., "Polymer optical fibres: conventional and microstructured fibres," in Fiber Lasers IX: Technology, Systems, and Applications, vol. 8237 of Proceedings of SPIE, 2012.

[97] J. Witt, M. Breithaupt, J. Erdmann, and K. Krebber, "Humidity sensing based on microstructured POF long period gratings," in Proceedings of the International Conference on Plastic Optical Fibres, pp. 409-414, 2011.

[98] D. Sáez-Rodríguez, J. L. Cruz, I. Johnson, D. J. Webb, M. C. J. Large, and A. Argyros, "Water diffusion into UV inscripted long period grating in microstructured polymer fiber," IEEE Sensors Journal, vol. 10, no. 7, pp. 1169-1173, 2010.

[99] M. A. Van Eijkelenborg, W. Padden, and J. A. Besley, "Mechanically induced long-period gratings in microstructured polymer fibre," Optics Communications, vol. 236, no. 1-3, pp. 75-78, 2004.

[100] M. M. Werneck, R. C. Allil, D. M. C. Rodrigues et al., "LPG and taper based fiber-optic sensor for index of refraction measurements in biosensor applications," in Proceedings of the International Conference on Plastic Optical Fibres, pp. 545-550, 2011.

[101] J. Witt, M. Schukar, K. Krebber, J. Demuth, and L. Sasek, "Heart rate sensor for integration into personal protective equipment," in Proceedings of the International Conference on Plastic Optical Fibres, pp. 573-577, 2011.

[102] K. E. Carroll, C. Zhang, D. J. Webb, K. Kalli, A. Argyros, and M. C. J. Large, "Thermal response of Bragg gratings in PMMA microstructured optical fibers," Optics Express, vol. 15, no. 14, pp. 8844-8850, 2007. 
[103] I. P. Johnson, K. Kalli, and D. J. Webb, "827nm Bragg grating sensor in multimode microstructured polymer optical fibre," Electronics Letters, vol. 46, no. 17, pp. 1217-1218, 2010.

[104] I. P. Johnson, D. J. Webb, and K. Kalli, "Utilisation of thermal annealing to record multiplexed FBG sensors in multimode microstructured polymer optical fibre," in 21st International Conference on Optical Fiber Sensors, vol. 7753 of Proceedings of SPIE, 77536T, 2011.

[105] D. Barrera, I. P. Johnson, D. J. Webb, B. Van Hoe, G. Van Steenberge, and S. Sales, "Dynamic strain sensor using a VCSEL and a polymer fiber Bragg grating in a multimode fiber," in Proceedings of the International Conference on Plastic Optical Fibres, pp. 563-567, 2011.

[106] I. P. Johnson, D. J. Webb, K. Kalli et al., "Polymer PCF Bragg grating sensors based on poly(methyl methacrylate) and TOPAS cyclic olefin copolymer," in Optical Sensors and Photonic Crystal Fibers V, vol. 8073 of Proceedings of SPIE, 80732V-1, 2011.

[107] W. Yuan, L. Khan, D. J. Webb et al., "Humidity insensitive TOPAS polymer fiber Bragg grating sensor," Optics Express, vol. 19, no. 20, pp. 19731-19739, 2011.

[108] I. P. Johnson, W. Yuan, A. Stefani et al., "Optical fibre Bragg grating recorded in TOPAS cyclic olefin copolymer," Electronics Letters, vol. 47, no. 4, pp. 271-272, 2011.

[109] A. Stefani, W. Yuan, C. Markos, and O. Bang, "Narrow bandwidth 850-nm fiber Bragg gratings in few-mode polymer optical fibers," IEEE Photonics Technology Letters, vol. 23, no. 10, pp. 660-662, 2011.

[110] C. Zhang, W. Zhang, D. J. Webb, and G. D. Peng, "Optical fibre temperature and humidity sensor," Electronics Letters, vol. 46, no. 9, pp. 643-644, 2010.

[111] A. Othonos and K. Kalli, Fiber Bragg Gratings, Artech House, Norwood, UK, 1999.

[112] M. A. Van Eijkelenborg, A. Argyros, A. Bachmann et al., "Bandwidth and loss measurements of graded-index microstructured polymer optical fibre," Electronics Letters, vol. 40, no. 10, pp. 592-593, 2004.

[113] R. Kruglov, S. Loquai, C. A. Bunge, O. Ziemann, B. Schmauss, and J. Vinogradov, "10 Gbit/s short-reach transmission over $35 \mathrm{~m}$ large-core graded-index polymer optical fiber," in Proceedings of the Optical Fiber Communication Conference (OFC '11), OThZ6, March 2011.

[114] J. Vinogradov, R. Kruglov, S. Loquai, and O. Ziemann, "Multigigabit transmission with blue, green and red laser diodes," in Proceedings of the International Conference on Plastic Optical Fibres, pp. 467-470, 2011.

[115] R. Lwin, G. Barton, L. Harvey et al., "Beyond the bandwidthlength product: graded index microstructured polymer optical fiber," Applied Physics Letters, vol. 91, no. 19, Article ID 191119, 2007.

[116] A. Argyros, R. Lwin, and M. C. J. Large, "Bend loss in highly multimode fibres," Optics Express, vol. 16, no. 23, pp. 1859018598, 2008.

[117] D. Li and L. Wang, "Fluorescence hydrogen peroxide probe based on a microstructured polymer optical fiber modified with a titanium dioxide film," Applied Spectroscopy, vol. 64, no. 5, pp. 514-519, 2010.

[118] D. Li and L. Wang, "Cellulose acetate polymer film modified microstructured polymer optical fiber towards a nitrite optical probe," Optics Communications, vol. 283, no. 14, pp. 2841-2844, 2010.
[119] C. M. B. Cordeiro, M. A. R. Franco, G. Chesini et al., "Microstructured-core optical fibre for evanescent sensing applications," Optics Express, vol. 14, no. 26, pp. 13056-13066, 2006.

[120] F. M. Cox, R. Lwin, M. C. J. Large, and C. M. B. Cordeiro, “Opening up optical fibres," Optics Express, vol. 15, no. 19, pp. 11843-11848, 2007.

[121] A. Wang, A. Docherty, B. T. Kuhlmey, F. M. Cox, and M. C. J. Large, "Side-hole fiber sensor based on surface plasmon resonance," Optics Letters, vol. 34, no. 24, pp. 3890-3892, 2009.

[122] X. Yang and L. Wang, "Silver nanocrystals modified microstructured polymer optical fibres for chemical and optical sensing," Optics Communications, vol. 280, no. 2, pp. 368-373, 2007.

[123] F. M. Cox, A. Argyros, and M. C. J. Large, "Liquid-filled hollow core microstructured polymer optical fiber," Optics Express, vol. 14, no. 9, pp. 4135-4140, 2006.

[124] F. M. Cox, A. Argyros, M. C. J. Large, and S. Kalluri, "Surface enhanced Raman scattering in a hollow core microstructured optical fiber," Optics Express, vol. 15, no. 21, pp. 13675-13681, 2007.

[125] C. Rajapakse, F. Wang, T. C. Y. Tang, P. J. Reece, S. G. Leon-Saval, and A. Argyros, "Spectroscopy of 3D-trapped particles inside a hollow-core microstructured optical fiber," Optics Express, vol. 20, no. 10, pp. 11232-11240, 2012.

[126] P. J. Roberts, F. Couny, H. Sabert et al., "Ultimate low loss of hollow-core photonic crystal fibres," Optics Express, vol. 13, no. 1, pp. 236-244, 2005.

[127] F. Couny, F. Benabid, P. J. Roberts, M. T. Burnett, and S. A. Maier, "Identification of Bloch-modes in hollow-core photonic crystal fiber cladding," Optics Express, vol. 15, no. 2, pp. 325-338, 2007.

[128] F. Benabid, J. C. Knight, G. Antonopoulos, and P. S. J. Russell, "Stimulated Raman scattering in hydrogen-filled hollow-core photonic crystal fiber," Science, vol. 298, no. 5592, pp. 399-402, 2002.

[129] F. Couny, F. Benabid, and P. S. Light, "Large-pitch kagomestructured hollow-core photonic crystal fiber," Optics Letters, vol. 31, no. 24, pp. 3574-3576, 2006.

[130] F. Couny, F. Benabid, P. J. Roberts, P. S. Light, and M. G. Raymer, "Generation and photonic guidance of multi-octave opticalfrequency combs," Science, vol. 318, no. 5853, pp. 1118-1121, 2007.

[131] F. Couny, P. J. Roberts, T. A. Birks, and F. Benabid, "Squarelattice large-pitch hollow-core photonic crystal fiber," Optics Express, vol. 16, no. 25, pp. 20626-20636, 2008.

[132] T. D. Hedley, D. M. Bird, F. Benabid, J. C. Knight, and P. S. J. Russell, "Modelling of a novel hollow-core photonic crystal fibre," in Proceedings of the Quantum electronics and Laser Science (QELS '03), p. 2, June 2003.

[133] G. J. Pearce, G. S. Wiederhecker, C. G. Poulton, S. Burger, and P. S. J. Russell, "Models for guidance in kagome-structured hollow-core photonic crystal fibres," Optics Express, vol. 15, no. 20, pp. 12680-12685, 2007.

[134] Y. Y. Wang, N. V. Wheeler, F. Couny, P. J. Roberts, and F. Benabid, "Low loss broadband transmission in hypocycloidcore Kagome hollow-core photonic crystal fiber," Optics Letters, vol. 36, no. 5, pp. 669-671, 2011.

[135] K. Wang and D. M. Mittleman, "Metal wires for terahertz wave guiding," Nature, vol. 432, no. 7015, pp. 376-379, 2004.

[136] R. Mendis and D. Grischkowsky, "Undistorted guided-wave propagation of subpicosecond terahertz pulses," Optics Letters, vol. 26, no. 11, pp. 846-848, 2001. 
[137] R. W. McGowan, G. Gallot, and D. Grischkowsky, "Propagation of ultrawideband short pulses of terahertz radiation through submillimeter-diameter circular waveguides," Optics Letters, vol. 24, no. 20, pp. 1431-1433, 1999.

[138] J. A. Harrington, R. George, P. Pedersen, and E. Mueller, "Hollow polycarbonate waveguides with inner $\mathrm{Cu}$ coatings for delivery of terahertz radiation," Optics Express, vol. 12, no. 21, pp. 5263-5268, 2004.

[139] A. Hassani, A. Dupuis, and M. Skorobogatiy, "Low loss porous terahertz fibers containing multiple subwavelength holes," Applied Physics Letters, vol. 92, no. 7, Article ID 071101, 2008.

[140] A. Hassani, A. Dupuis, and M. Skorobogatiy, "Porous polymer fibers for low-loss Terahertz guiding," Optics Express, vol. 16, no. 9, pp. 6340-6351, 2008.

[141] S. Atakaramians, V. Shahraam Afshar, B. M. Fischer, D. Abbott, and T. M. Monro, "Porous fibers: a novel approach to low loss THz waveguides," Optics Express, vol. 16, no. 12, pp. 8845-8854, 2008.

[142] S. Atakaramians, S. Afshar, B. M. Fischer, D. Abbott, and T. M. Monro, "Low loss, low dispersion and highly birefringent terahertz porous fibers," Optics Communications, vol. 282, no. 1, pp. 36-38, 2009.

[143] S. Atakaramians, S. V. Afshar, H. Ebendorff-Heidepriem et al., "THz porous fibers: design, fabrication and experimental characterization," Optics Express, vol. 17, no. 16, pp. 14053-14062, 2009.

[144] S. Atakaramians, S. Afshar, M. Nagel et al., "Direct probing of evanescent field for characterization of porous terahertz fibers," Applied Physics Letters, vol. 98, no. 12, Article ID 121104, 2011.

[145] C. S. Ponseca, R. Pobre, E. Estacio et al., "Transmission of terahertz radiation using a microstructured polymer optical fiber," Optics Letters, vol. 33, no. 9, pp. 902-904, 2008.

[146] A. Dupuis, K. Stoeffler, B. Ung, C. Dubois, and M. Skorobogatiy, "Transmission measurements of hollow-core THz Bragg fibers," Journal of the Optical Society of America B, vol. 28, no. 4, pp. 896-907, 2011.

[147] B. Ung, A. Dupuis, K. Stoeffler, C. Dubois, and M. Skorobogatiy, "High-refractive-index composite materials for terahertz waveguides: trade-off between index contrast and absorption loss," Journal of the Optical Society of America B, vol. 28, no. 4, pp. 917-921, 2011.

[148] R. Amezcua-Correa, F. Gérôme, S. G. Leon-Saval, N. G. R. Broderick, T. A. Birks, and J. C. Knight, "Control of surface modes in low loss hollow-core photonic bandgap fibers," Optics Express, vol. 16, no. 2, pp. 1142-1149, 2008.

[149] D. S. Wu, A. Argyros, and S. G. Leon-Saval, "Reducing the size of hollow terahertz waveguides," Journal of Lightwave Technology, vol. 29, no. 1, Article ID 5638593, pp. 93-103, 2011.

[150] J. Anthony, R. Leonhardt, S. G. Leon-Saval, and A. Argyros, "THz propagation in kagome hollow-core microstructured fibers," Optics Express, vol. 19, no. 19, pp. 18470-18478.

[151] A. D. Pryamikov, A. S. Biriukov, A. F. Kosolapov, V. G. Plotnichenko, S. L. Semjonov, and E. M. Dianov, "Demonstration of a waveguide regime for a silica hollow-core microstructured optical fiber with a negative curvature of the core boundary in the spectral region $>3.5 \mu \mathrm{m}$," Optics Express, vol. 19, no. 2, pp. 1441-1448, 2011.

[152] F. Yu, W. J. Wadsworth, and J. C. Knight, "Low loss silica hollow core fibers for 3-4 $\mu \mathrm{m}$ spectral region," Optics Express, vol. 20, no. 10, pp. 11153-11158, 2012.
[153] L. Vincetti, "Numerical analysis of plastic hollow core microstructured fiber for Terahertz applications," Optical Fiber Technology, vol. 15, no. 4, pp. 398-401, 2009.

[154] L. Vincetti, V. Setti, and M. Zoboli, "Terahertz tube lattice fibers with octagonal symmetry," IEEE Photonics Technology Letters, vol. 22, no. 13, pp. 972-974, 2010.

[155] L. Vincetti, "Single-mode propagation in triangular tube lattice hollow-core terahertz fibers," Optics Communications, vol. 283, no. 6, pp. 979-984, 2010.

[156] L. Vincetti and V. Setti, "Waveguiding mechanism in tube lattice fibers," Optics Express, vol. 18, no. 22, pp. 23133-23146, 2010.

[157] L. Vincetti and V. Setti, "Extra loss due to Fano resonances in inhibited coupling fibers based on a lattice of tubes," Optics Express, vol. 20, no. 13, pp. 14350-14361, 2012.

[158] L. Vincetti and V. Setti, "Confinement loss in kagome and tube lattice fibers: comparison and analysis," Journal of Lightwave Technology, vol. 30, no. 10, pp. 1470-1474, 2012.

[159] J. B. Pendry, A. J. Holden, W. J. Stewart, and I. Youngs, "Extremely low frequency plasmons in metallic mesostructures," Physical Review Letters, vol. 76, no. 25, pp. 4773-4776, 1996.

[160] S. I. Maslovski and M. G. Silveirinha, "Nonlocal permittivity from a quasistatic model for a class of wire media," Physical Review B, vol. 80, no. 24, Article ID 245101, 2009.

[161] M. A. Schmidt, L. N. Prill Sempere, H. K. Tyagi, C. G. Poulton, and P. S. J. Russell, "Waveguiding and plasmon resonances in two-dimensional photonic lattices of gold and silver nanowires," Physical Review B, vol. 77, no. 3, Article ID 033417, 2008.

[162] J. Hou, D. Bird, A. George, S. Maier, B. T. Kuhlmey, and J. C. Knight, "Metallic mode confinement in microstructured fibres," Optics Express, vol. 16, no. 9, pp. 5983-5990, 2008.

[163] J. D. Baena, R. Marqués, F. Medina, and J. Martel, "Artificial magnetic metamaterial design by using spiral resonators," Physical Review B, vol. 69, no. 1, Article ID 014402, pp. 144021144025, 2004.

[164] E. J. Smith, Z. Liu, Y. Mei, and O. G. Schmidt, "Combined surface plasmon and classical waveguiding through metamaterial fiber design," Nano Letters, vol. 10, no. 1, pp. 1-5, 2010.

[165] A. Ishikawa, S. Zhang, D. A. Genov, G. Bartal, and X. Zhang, "Deep subwavelength terahertz waveguides using gap magnetic plasmon," Physical Review Letters, vol. 102, no. 4, Article ID 043904, 2009.

[166] S. Atakaramians, A. Argyros, S. C. Fleming, and B. T. Kuhlmey, "Hollow-core waveguides with uniaxial metamaterial cladding: mode equations and guidance conditions," Journal of the Optical Society of America B, vol. 29, no. 9, pp. 2462-2477, 2012.

[167] E. Badinter, A. Ioisher, E. Monaico, V. Postolache, and I. M. Tiginyanu, "Exceptional integration of metal or semimetal nanowires in human-hair-like glass fiber," Materials Letters, vol. 64, no. 17, pp. 1902-1904, 2010. 

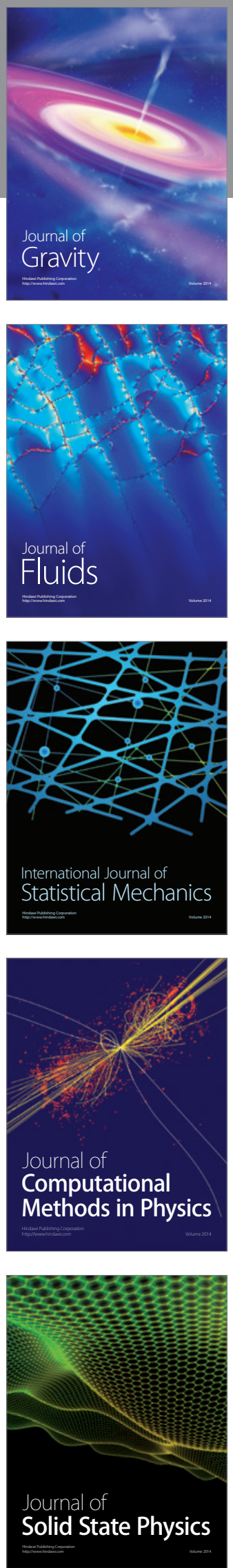

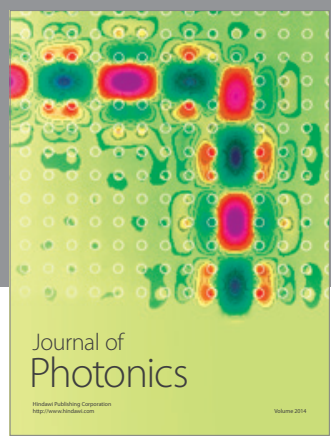

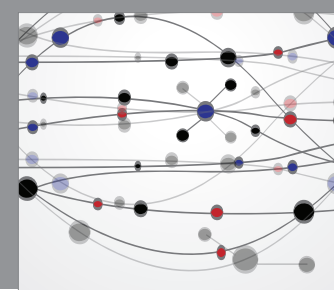

The Scientific World Journal

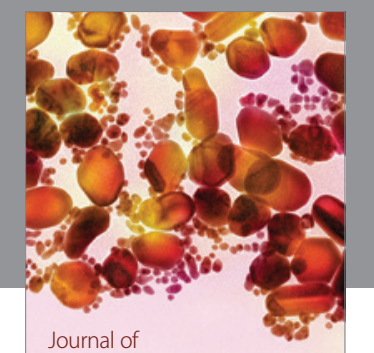

Soft Matter
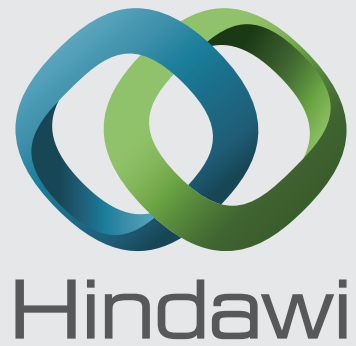

Submit your manuscripts at

http://www.hindawi.com
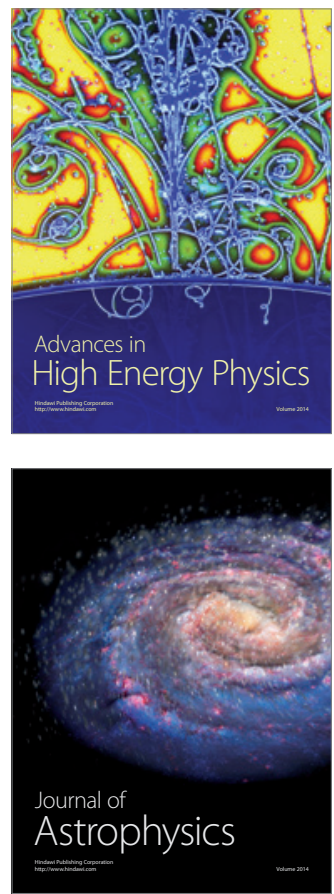
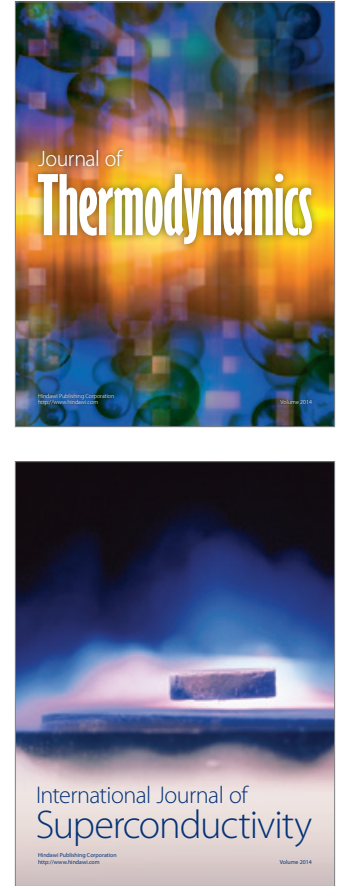
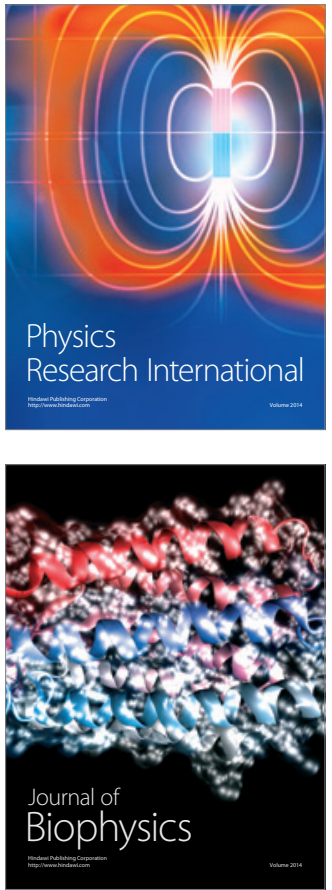
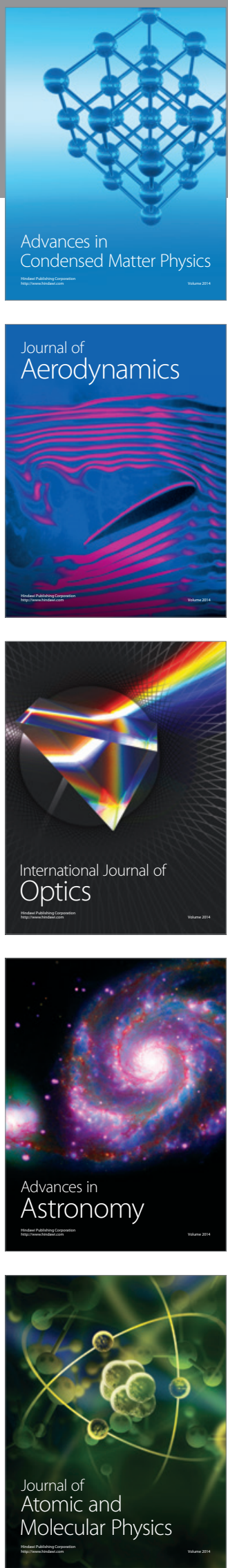